\title{
Framework for the optimization of operation and design of systems with different alternative water sources
}

\author{
Lisa J. Blinco ${ }^{1,2^{*}}$ (D), Martin F. Lambert ${ }^{1,2}$, Angus R. Simpson ${ }^{1,2}$ and Angela Marchi ${ }^{1,2}$
}

\begin{abstract}
Water security has become an increasing concern for many water system managers due to climate change and increased population. In order to improve the security of supply, alternative sources such as harvested stormwater, recycled wastewater and desalination are becoming more commonly used. This brings about the need for tools to analyze and optimize systems that use such sources, which are generally more complex than traditional water systems. Previous methodologies have been limited in their scope and cannot be applied to all types of water sources and systems. The framework presented in this paper has been developed for holistic analysis and optimization of water supply and distribution systems that use alternative water sources. It includes both design and operational decision variables, water and energy infrastructure, simulation of systems, analysis of constraints and objectives, as well as policies and regulations which may affect any of these factors. This framework will allow users to develop a comprehensive analysis and/or optimization of their water supply system, taking into account multiple types of water sources and consumers, the effect of their own design and operational decisions, and the impact of government policies and different energy supply options. Two case study systems illustrate the application of the framework; the first case study is a harvested stormwater system that is used to demonstrate the importance of simulation and analysis prior to optimization, the second utilizes four different water sources to increase security of supply and was optimized to reduce pump energy use.
\end{abstract}

Keywords: Water distribution systems, Integrated water resources management, Decision-making, Conceptual framework, Alternative water sources, Optimization

\section{Introduction}

A changing climate and increasing population have put a strain on traditional water resources, which typically rely on natural catchment water. This has made water security an increasing concern for many water system managers, who have investigated options for reducing demand and supplementing supply. Alternative water sources, such as harvested stormwater, recycled wastewater and desalination, are increasingly being used to improve water security of cities and towns. Methods for simulation, analysis and optimization of traditional potable water distribution systems (WDSs) cannot

\footnotetext{
* Correspondence: lisa.blinco@adelaide.edu.au

${ }^{1}$ School of Civil, Environmental and Mining Engineering, The University of Adelaide, Engineering North N136, North Terrace Campus, Adelaide, South Australia 5005, Australia

${ }^{2}$ Cooperative Research Centre for Water Sensitive Cities, Monash University LPO, PO BOX 8000, Clayton, Victoria 3800, Australia
}

necessarily be directly transferred to systems that use alternative water sources. Therefore there is a need to develop a methodology specifically for alternative water source systems, which includes both hydraulic and hydrologic considerations, as well as the many additional parameters and variables associated with alternative water sources. There are many modelling tools used in current practice for integrated water management, such as eWater Source, WEAP (Water Evaluation and Planning System) and Mike Basin. These modelling tools do not include hydraulic simulation, and therefore may not accurately represent performance of urban water networks. Moreover, this framework is not software, rather its purpose is to guide water system managers in how to best simulate and optimize their systems, particularly those that integrate multiple water sources, and natural and human-made systems. The framework should be 
used to determine which system components need to be modelled, which type of modelling tools are most appropriate, what regulations and policies need to be taken into account and how to evaluate the performance of the system.

The framework introduced in this paper can be applied to the optimization of the design and operation of water supply and distribution systems from source to consumer, considering multiple traditional and alternative sources, multiple uses and multiple objectives. Electrical energy sources and their effect on electricity prices and greenhouse gas (GHG) emissions are included, as are several types of government policies that may affect the design, operation, data and evaluation of the system. The objectives of this paper are to (1) develop a generalized framework that could be applied to any water supply and/or distribution system optimization problem and (2) outline the application of this framework to two case study systems with a focus on optimizing their operation.

\section{Literature review}

Since 2000, there has been significant consideration of the concept of water security (Cook and Bakker 2012) as water is increasingly seen as a fundamental and finite resource (Bogardi et al. 2012). Consequently, the use of alternative sources, such as harvested stormwater, desalination, recycled wastewater and rainwater, has gained traction (Fielding et al. 2015). Harvested stormwater schemes are often decentralized and used for nonpotable supply such as household gardening and irrigation of public reserves (Naylor et al. 2012), however, in some cases are also used for potable supply (McArdle et al. 2011). While desalination is a climate independent (and therefore more reliable) source, is often not the most cost effective or environmentally sensitive option (Becker et al. 2010; Miller et al. 2015). Recycled wastewater is also climate independent, and generally used for large scale non-potable applications (Muga and Mihelcic 2008; Oron et al. 2014), however, it can also be used for indirect or direct potable supply (Rodriguez et al. 2009; Nagal 2015). Domestic rainwater tanks are increasing in popularity and have benefits of reducing water usage from utilities and reducing stormwater runoff from houses (Campisano and Modic 2012; Umapathi et al. 2013). Demand management strategies have also been used to reduce per capita consumption and therefore reduce the pressure on limited water supplies (Dawadi and Ahmad 2013; Friedman et al. 2014).

Some alternative sources, such as harvested stormwater, introduce additional complexity to the problem of modeling and optimization than has been previously considered for traditional water systems (Marchi et al. 2016). There is, for example, the need to consider the supply and distribution systems together, rather than separately, as it is less likely that there will be large storages isolating the supply side from the distribution side. When including the supply side, longer simulation times often need to be used, requiring rainfall and evaporation scenarios to be taken into account. The security of supply with regard to climate change needs to be considered (Paton et al. 2014; Cai et al. 2015), as some sources are climate dependent and some are climate independent. The social acceptability of using particular sources for particular applications and the willingness of consumers to pay more for alternative source systems to be constructed and maintained may need to be incorporated (Hwang et al. 2006; Londoño Cadavid and Ando 2013; Fielding et al. 2015). The perception of risks associated with alternative water source systems by water system managers may also present a barrier to the implementation and success of such systems (Dobbie and Brown 2012; West et al. 2016). Many alternative sources also have associated externalities that result in either cost or benefit to the user, such as reduced effluent flow to the ocean or receiving water body by reusing wastewater and reduced urban stream flows by harvesting stormwater (Marchi et al. 2016).

The increased use of alternative water sources then raises the question of how such systems should by analyzed and optimized to ensure they are implemented as effectively as possible. Stokes et al. (2014) developed a framework for optimizing the cost and GHG emissions of WDSs, taking into account both the design and operation of the system, energy sources and GHG emission factors. This study, however, was applicable only to traditional WDSs, with no consideration of the supply side and alternative water sources. Chung et al. (2008) developed a mathematical model for evaluating integrated water supply systems with decentralized treatments. Multiple sources, uses, transportation and treatment systems can be considered, however only surface water, groundwater and recycled wastewater sources are included. This model does not incorporate any optimization procedure, only analysis of different options developed by the user. Makropoulos et al. (2008), with further developments in Rozos and Makropoulos (2013), produced a decision-support tool for modeling the urban water system from source to tap. The software can be used to select combinations of water saving strategies and technologies, including how much water from each type of demand (for example domestic, commercial) is obtained from each source and how the system is operated. It uses a demand-oriented, water balance approach and does not include capability for other types of simulation models such as hydraulic and hydrologic modeling. 
Uncertainty, particularly with regard to climate change, is an important consideration that has been taken into account in several methodologies. Paton et al. (2014) developed a framework for water supply system planning with alternative sources and climate change considerations, while Beh et al. (2014, 2015) developed two methods for optimal sequencing of urban water supply augmentation options under deep uncertainty regarding demands and climate. The research by both Paton et al. (2014) and Beh et al. $(2014,2015)$ considered only the planning of water supply projects, and did not optimize the specific design or operation of the systems. Sequencing is also considered in Cai et al. (2015), however, in this case it is applied to planning of drought mitigation strategies in agricultural systems. They consider multiple decision stages in which options such as infiltration ponds, parallel terraces, irrigation triggering threshold and irrigation water sources can be implemented. Marchi et al. (2016) developed a methodology for optimizing the design of harvested stormwater systems taking into account future climate scenarios; however, it does not apply to other types of alternative sources or optimization of system operation. It does include a detailed analysis of the associated externalities, such as reduced peak flows and improved economic value of properties near stormwater schemes. Ashbolt et al. (2014) introduced a framework for planning of short- term operations for water systems using surface water, groundwater, desalination, and recycled wastewater with multiple objectives and multiple inflow replicates to account for uncertainty. Long-term operating strategies and the design of the system were not included and the operating strategies considered were limited to bulk water transfers and not the operation of pumps and smaller storages.

\section{Framework for the optimization of alternative water source systems}

The framework presented in the current paper was developed to guide the modeling and optimization of water supply and distribution systems that use alternative water sources. It is comprised of several components and sub-components that fit within an optimization structure, for example, a multi-objective evolutionary algorithm (Fig. 1). The options component [OPT] describes the potential 'decision variables' that are available in an optimization problem, that is, the factors that can be changed in order to produce a different outcome. This includes both the initial design of the water supply and distribution infrastructure and the long- and short-term rules that govern the operation of the system once it has been commissioned. The infrastructure component [INF] describes the physical components of the system that need to be modeled and the

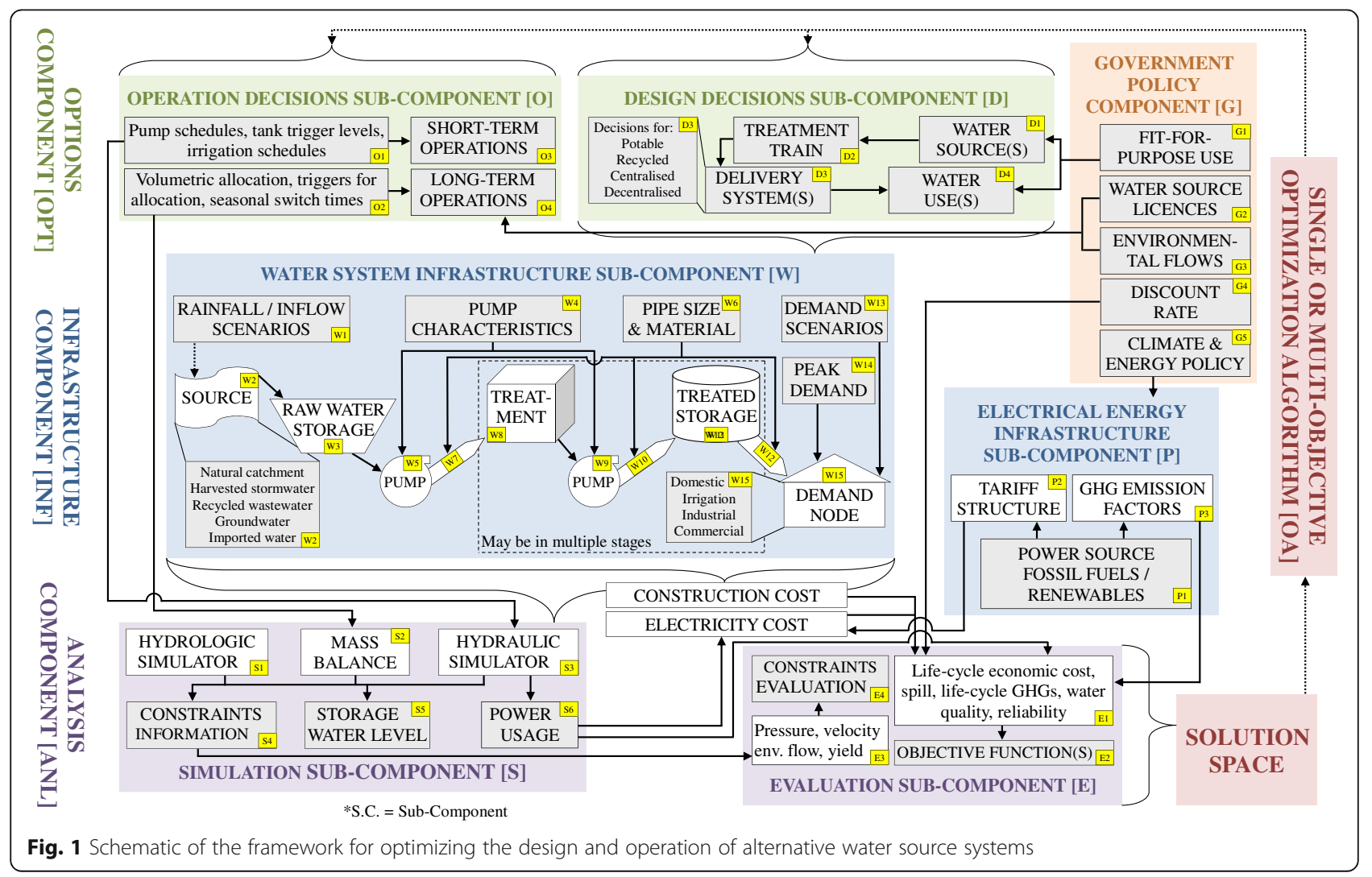


data associated with each, including both water infrastructure and energy infrastructure, which may affect the evaluation of electrical energy cost and life-cycle GHG emissions. There is also a government policy component [G] that covers the policies from regulating bodies that may affect other aspects of the framework. The analysis component [ANL] describes the simulation of each potential system configuration and evaluation against objectives and constraints. The optimization algorithm $[\mathrm{OA}]$ investigates different possible combinations of decision variables from the options component, models the system according to the infrastructure component and evaluates it using the analysis component to find the optimal solution(s).

Details of the components and sub-components are shown in Fig. 1 and described in Sections 'Options component [OPT],' 'Infrastructure component [INF]', 'Government policy component [G]' and 'Analysis component [ANL]'. Table 1 summarizes the parameters that need to be considered in the optimization and simulation of alternative water source systems with respect to the different items that are presented in Fig. 1 and in the following sections. There are three (non-exclusive) categories that each parameter may be placed in - decision variables, parameters that are set, and uncertain parameters. Decision variables are parameters that the user may be able to examine using optimization. It is important to note that in most optimization problems, not all of these parameters will be available as decision variables at once, and it is likely that only a small number will be considered. For example, when optimizing pump operations for an irrigation system, only the first three 'decision variables' shown in Table 1 (pump schedules, tank trigger levels, and demand scheduling) may be considered. The remaining parameters that are designated as decision variables in Table 1, particularly those relating to the design of the system (for example, delivery system layout and pump sizing) would already be set and not able to be optimized if the existing infrastructure cannot be modified. The parameters that are set are those that very rarely, if ever, are able to be optimized by the user. These include parameters that would be controlled by external sources, for example consumers of domestic or commercial demands, pipe manufacturers and higher level government and regulatory bodies; and also parameters that need to be predefined to a known or assumed value before optimization or simulation can be performed, for example, fire demand/reserve, hydrologic/ hydraulic variables and objective and constraint selection and definition. The final category, uncertainty, designates those externally set or predefined variables that are not well known or may be subject to change in the future and therefore may need to be considered in a sensitivity analysis. While the selected values of decision variables have an impact on the performance of a system, they are generally within the control of the decision maker, and therefore are not classed as 'uncertain'. It is important to note that the categorization in this table is indented as an indication of how each parameter is typically treated. There are, of course, exceptions to this, as almost all of the parameters could be considered as decision variables if desired and have some associated uncertainty. For example, environmental flows have been designated as an externally set parameter, as it is likely that the operator of a system will have to meet requirements set by an external organization such as the Environmental Protection Agency. They may, however, want to investigate providing greater environmental flows, or show the benefits of reducing their environmental flow requirements and being able to supply more water elsewhere.

\section{Options component [OPT]}

The options component covers the potential decision variables (and the range of possible choices for the decision variables) for an optimization problem. This component is split into two sub-components; the operational decisions sub-component $[\mathrm{O}]$ and the design decisions sub-component $[\mathrm{D}]$. Design decisions include elements that can be changed before a system is constructed, such as the layout and capacities, materials and other properties of the various infrastructure components. Operational decisions include elements that can be changed after construction during the daily management of the system, such as the operating rules for pumps and valves and allocation of water from different sources.

\section{Operational decisions Sub-component [O]}

Both short- and long-term operations are considered in the operational decisions sub-component. The critical aspects of this sub-component (items in bold can be optimized), as shown in Fig. 1 and Table 1 are:

[O1] the specific short term operating strategies including pump schedules (when pumps are turned on or off based on time), trigger levels (water levels in tanks or other storages that determine when pumps or valves turn on or off), irrigation or demand schedules (for systems where they can be pre-determined), valve settings and operating rules, and pressure settings for pumps (to maintain the set pressure at a particular point).

[O2] the specific long term operating strategies including volumetric allocation of water from different alternative sources, trigger levels (for example in reservoirs) that determine allocations from different sources or water demand restriction levels, switch 
Table 1 Summary of parameters for the design and operation of alternative water source systems

\begin{tabular}{|c|c|c|c|c|}
\hline Parameter & $\begin{array}{l}\text { Decision } \\
\text { variable }^{a}\end{array}$ & $\begin{array}{l}\text { Parameter } \\
\text { that is set }\end{array}$ & $\begin{array}{l}\text { Uncertain } \\
\text { parameter }\end{array}$ & $\begin{array}{l}\text { Relevant items } \\
\text { in Fig. } 1\end{array}$ \\
\hline \multicolumn{5}{|l|}{ Operational inputs [O] } \\
\hline Pump schedule & $x$ & & & 01 \\
\hline Tank trigger levels & $x$ & & & O1 \\
\hline Tank/storage maximum and minimum allowable levels & & $x$ & & O1, W3, W11 \\
\hline Demand pattern (irrigation, agriculture) & $x$ & & & O1, D4, W13 \\
\hline Demand pattern (domestic, commercial, industrial) & & $x$ & $x$ & O1, D4, W13 \\
\hline Demand flow rate (peak, average, peak day) & & $x$ & $x$ & O1, D4, W14 \\
\hline Valve settings or operating rules & $x$ & & & $\mathrm{O} 1$ \\
\hline Pump pressure settings & $x$ & & & $\mathrm{O} 1$ \\
\hline Volumetric allocation of water & $x$ & & & $\mathrm{O} 2$ \\
\hline Reservoir trigger levels & $x$ & & & $\mathrm{O} 2$ \\
\hline Switch time between operating regimes & $x$ & & & $\mathrm{O} 2$ \\
\hline Priority ranking of operating rules & & $x$ & & $\mathrm{O} 3, \mathrm{O} 4$ \\
\hline \multicolumn{5}{|l|}{ Design inputs [D] and water infrastructure [W] } \\
\hline Water source selection & $x$ & & & D1, W2 \\
\hline Water source infrastructure (layout, capacity) & $x$ & & & D1, W2 \\
\hline Treatment type selection & $x$ & & & D2, W8 \\
\hline Treatment infrastructure (layout, capacity, treatment rate/level) & $x$ & & & D2, W8 \\
\hline Delivery system type selection & $x$ & & & D3 \\
\hline Delivery system layout (lengths, elevations, junctions, tank locations) & $x$ & & & D3, W7, W10, W12, W15 \\
\hline Pipe material and diameters & $x$ & & & D3, W7, W10, W12 \\
\hline $\begin{array}{l}\text { Pipe parameters (unit cost, pipe wall roughness }(\varepsilon) \text {, } \\
\text { wall thickness, embodied energy) }\end{array}$ & & $x$ & $X(\varepsilon)$ & D3, W6, W7, W10, W12 \\
\hline Pump sizing & $x$ & & & D3, W5, W9 \\
\hline Pump performance characteristics and cost & & $x$ & & D3, W4 \\
\hline Tank sizing (capacity, height, diameter) & $x$ & & & D3, W3, W11 \\
\hline Fire demand/reserve & & $x$ & & D3, W11 \\
\hline Water user type selection & $x$ & & & D4 \\
\hline Rainfall/streamflow series & & $x$ & $x$ & W1 \\
\hline Reservoir capacity and volume curve & $x$ & & & W3 \\
\hline Pond (e.g. wetland) capacity and volume curve & $x$ & & & W3 \\
\hline Prioritization rules for demands types & & $x$ & & W15 \\
\hline \multicolumn{5}{|l|}{ Other inputs [P], [G] and [S] } \\
\hline Power source selection & & $x$ & $x$ & P1, P3, G5 \\
\hline Electricity tariff structure and cost & & $x$ & $x$ & P2 \\
\hline GHG emission factors & & $x$ & $x$ & P3, G5 \\
\hline Fit-for-purpose requirements & & $x$ & & G1 \\
\hline Water license amounts & & $x$ & & G2 \\
\hline Environmental flow amounts & & $x$ & & G3 \\
\hline Discount rate & & $x$ & $x$ & G4 \\
\hline Hydrologic variables (e.g. permeability) & & $x$ & & S1 \\
\hline Hydraulic variables (e.g. water temperature) & & $x$ & & S3 \\
\hline
\end{tabular}


Table 1 Summary of parameters for the design and operation of alternative water source systems (Continued)

\begin{tabular}{|c|c|c|}
\hline \multicolumn{3}{|l|}{ Optimization problem formulation [E] } \\
\hline \multicolumn{3}{|l|}{$\begin{array}{l}\text { Objective selection } \\
\text { Optimization problem formulation }[E]\end{array}$} \\
\hline Objective function(s) & $x$ & E2 \\
\hline Constraint selection & $x$ & E3 \\
\hline Constraint limits (maximum and minimum) & $x$ & E4 \\
\hline Penalty costs & $x$ & E4 \\
\hline
\end{tabular}

${ }^{a}$ Note: Parameters specified as decision variables are shown in bold throughout Sections 'Options component [OPT]' and 'Infrastructure component [INF]'

times between different operating regimes (for example between different trigger level sets for different seasons) and power source selection.

[O3] the overall short-term operating strategy, including operating rules that are optimized in $[\mathrm{O} 1]$ and operating rules that are pre-set and are not to be optimized (acting as constraints). Where there are multiple operating rules, the priority of each rule and order they are enforced in is important to consider.

[O4] the overall long-term operating strategy, including operating rules that are optimized in [O2] and operating rules that are pre-set and are not to be optimized. Again, the priority and order of the rules is important to consider.

Most systems have multiple operating conditions to meet and therefore multiple operating rules will be in place. Prioritization of the different operating rules is important, and this may be set by the operator or be chosen by the optimization tool. This component requires information from the government policy subcomponent ([G] in Fig. 1), specifically in terms of water source licensing and environmental flow regulations. These policies would typically be regulated by local or state government departments or the environmental protection authority. Operational rules set in this subcomponent will inform the simulation sub-component $[\mathrm{S}]$ as they will need to be represented in any simulation model(s) of the system.

\section{Design decisions Sub-component [D]}

This sub-component incorporates all of the design decisions that are available to the designer for the entire water supply and distribution system, from source to user. The critical aspects of this sub-component (items in bold can be optimized), as shown in Fig. 1 and Table 1 are:

[D1] the water sources selected to be used including natural catchments, harvested stormwater, recycled wastewater, groundwater, imported water, domestic rainwater, desalination, domestic greywater and sewer mining; and the layout and capacity of source infrastructure.
[D2] the types of treatment selected including centralized treatment at plants such as mechanical filtration, chemical dosing, ultraviolet treatment and ozonation, and decentralized in situ treatments such as gross pollutant traps, wetlands and biofilters; and the layout, capacity, dosing rates and retention times for treatment facilities.

[D3] the type and configuration of the delivery system used including potable, non-potable (for example dual reticulation systems to deliver recycled water), centralized and decentralized, and the infrastructure design variables such as system layout, pipe sizes, lengths and materials, pump sizing, valve sizing, and tank sizing.

[D4] the types of water users that are supplied by the system including potable, irrigation, agriculture, industrial, non-potable domestic/commercial and firefighting, and the demand rate and pattern for water use (for example, scheduling of irrigation demands).

Regulations on fit-for-purpose water use from the government policy component [G] in Fig. 1 inform what water sources can be used for particular applications and these are likely to be specified by state or federal government departments or health authorities. Generally, sources such as harvested stormwater and recycled wastewater cannot be used for potable supply and rather serve non-potable demands in dual-reticulation systems or are supplied to irrigation, agricultural and industrial users. There may be some systems, however, in which necessary approvals have been obtained to use these sources for potable supply. The design decisions are inputs to the water system infrastructure subcomponent $[\mathrm{W}]$ which describes the system elements and data to be modeled.

\section{Infrastructure component [INF]}

The purpose of this component is to describe the infrastructure that needs to be modeled in order to evaluate the objectives and constraints of the problem. There are two sub-components; the water system infrastructure sub-component $[\mathrm{W}]$ and the electrical energy infrastructure sub-component $[\mathrm{P}]$. Water system infrastructure 
includes the specific aspects of the water supply and distribution system and the data required, including construction and maintenance costs. Electrical energy infrastructure includes the power source (fossil fuel types and renewable types) and the electricity price and GHG emission factor data needed.

\section{Water system infrastructure Sub-component [W]}

This sub-component includes the specific infrastructure aspects of the water system design and the relevant data that is needed in order to simulate it. Most systems and optimization problems will not require all of these factors to be considered or modeled; however, the purpose of this framework is to cover a large range of the possible requirements for an optimization and hence the scope is intentionally broad.

The water system infrastructure sub-component [W] as shown in Fig. 1 represents a system with one water source, one treatment plant, one storage tank and one demand node. In reality, many systems will have more than one of each of these components, particularly the treated storage [W11] and demand node [W15]. Pumping of water between storages may occur in multiple stages, particularly when there is a large difference in elevation. For typical centralized potable WDSs, all treatment will occur at one water treatment plant. In decentralized systems such as for harvested stormwater schemes, however, treatment may occur in multiple stages. For example, a gross pollutant trap may be located on an urban creek before the water is collected in a harvest pond, then the water may be pumped to be treated through a wetland, and then treated again in a treatment plant.

The critical aspects of this sub-component (items in bold can be optimized) as shown in Fig. 1 and Table 1 are:

[W1] the rainfall or inflow scenarios for the water source; for example rainfall or streamflow scenarios for natural catchments and stormwater sources, or a sewer system flow pattern for recycled wastewater. Sources such as desalination and, depending on the temporal scale of the optimization, groundwater, do not usually require an inflow scenario. Rainfall and streamflow scenarios may be a data series obtained from measurements at gauging stations or modeled in a hydrologic simulation program [S1]. Multiple inflow scenarios may be used, particularly for systems with highly variable inflows. Losses such as evaporation and infiltration may also need to be taken into account for sources with large open storages such as reservoirs and natural water ways.

[W2] the source type as described in [D1] with input from [W1].
[W3] the raw water storage; this may be a reservoir (typical for a natural catchment), a harvest pond for a stormwater system, a tank (for example for a recycled wastewater system) or an aquifer for groundwater. Associated data including capacity, a volume curve, elevation, height and diameter is required.

[W4] characteristics of available pumps such as performance curves (head, efficiency, and power against flow), cost, rated speed and variable speed pump (VSP) information where applicable.

[W5] the pump transferring water from the raw water storage to a treatment facility, requiring data from [W4].

[W6] pipe size and material information such as available diameters, unit costs, pipe wall roughness, wall thickness and embodied energy. For new pipes, this information will be easily obtained from the pipe manufacturer. For existing systems, however, there may be some uncertainty in these parameters if detailed records of the 'as constructed' system and any pipe replacements have not been kept. In addition to this, the pipe wall roughness of existing pipes will generally be uncertain. Pipe wall roughness increase as pipes age, and pipe condition assessment may be needed to provide an estimate.

[W7] the pipe system transferring water from the raw water storage to the treatment facility, pipe lengths and layouts need to be known as well as information from [W6].

[W8] the treatment facility that will produce water of the required quality based on the source type and demand type. Characteristics of the individual treatment methods as described in [D2] need to be known.

[W9] the pump transferring water to a treated storage, requiring the same data as [W5].

[W10] the pipe system transferring water to a treated storage, with the same information as [W7] required.

[W11] the treated storage, for example, a tank or multiple tanks that are typically at a high elevation point of the network in order to supply demands by gravity. Data required includes the elevation, height, diameter and maximum and minimum allowable water levels.

[W12] the pipe system transferring water from the treated storage to consumers, which again requires information as in [W7]. This pipe system is likely to be more complex than those in [W7] and [W10], particularly for systems with many different demand nodes. For systems with only one source of water, [W7] and [W10] are 
likely to be single pipelines. For decentralized systems with only one specific consumer, [W12] will also most likely be a single pipeline. Most systems, however, have much more than one demand point and as such distribution systems are often looped or branched systems that require more complex analysis than single pipelines.

[W13] demand scenarios that will be applied to the demand nodes, consisting of a pattern of demand multipliers over a day, week or year. There may be multiple demand scenarios required for a system, for example, if there are different types of demand nodes (such as domestic, commercial, industrial) or different seasonal demands.

[W14] the peak demand is the demand rate that is typically used to size the system components and so will affect the design of the system. The demand scenarios [W13] are more likely to affect the operation of the system as the demand varies over the simulation time. The peak day demand (average demand over the peak day), the peak hour demand (the average demand over the hour with maximum consumption in the peak day) and average demand rates may also be required. Fire loading demands and other emergency conditions will affect the design of the system, for example storage tanks should be sized to be able to provide demand in the case of fires, other emergencies and system failures (e.g. if the supply to the tank is cut off).

[W15] the demand nodes for the consumers, these may be different types of users as described in [D4] and require information from [W13] and [W14]. Different types of users will have different demand rates [W14] and demand patterns [W13]. When simulating the system, an average demand rate will often be used with the demand pattern, rather than the peak demand. Systems with multiple demand nodes may prioritize different types of demands over other, for example, irrigation systems using non-potable water may prioritize high profile sport fields over reserves with no formal usage.

Choices made in the optimization of the design decisions sub-component [D] in Fig. 1 will be inputs to the water system infrastructure sub-component. There may be other parameters that are not decision variables in the optimization (as differentiated in Table 1) though are still required by this sub-component in order to simulate the system. The construction and maintenance costs of each of the infrastructure components needs to be known in order to calculate the initial construction cost and ongoing costs as part of life-cycle economic costing.
Information collected through this sub-component will be input to the simulation sub-component $[\mathrm{S}]$ depending on the types of simulation models used and to the evaluation sub-component [E] through the construction cost or other factors calculated for the specific objectives of a problem.

\section{Electrical energy infrastructure Sub-component [P]}

The electrical energy infrastructure sub-component includes any power infrastructure that affects the electricity prices and GHG emission factors. The critical aspects of this sub-component as shown in Fig. 1 and Table 1 are:

[P1] the breakdown of power sources including fossil fuel sources such as coal and oil, and renewable sources such as solar, wind and hydrothermal.

[P2] the electricity price tariff structure, which may be a peak and off-peak structure, or multi-part (more than two price levels) and could include a peak demand charge which applies to the peak electricity power usage in each month.

[P3] the GHG emission factor, which is based on the power source breakdown [P1] and may vary with time, either in the short-term (with sources that do not have storage such as solar panels and wind turbines) or the long-term (as fossil fuel sources tend to be phased out and renewable sources become more popular).

Climate and energy policy [G5] in the government policy component in Fig. 1 will affect the power source breakdown and electrical energy pricing now and into the future. This is likely to be regulated by a federal government department or body. Information from this sub-component is used to calculate electrical energy costs in order to evaluate life-cycle economic costs and also to calculate life-cycle GHG emissions in the evaluation sub-component [E].

\section{Government policy component [G]}

The government policy component covers policies by regulating bodies at any level (local, state, federal) that may affect other aspects of the framework. These policies need to be considered over the operational life-span of the system, for example, climate and energy policy may affect future energy sources and therefore affect future GHG emissions. The critical aspects of this component as shown in Fig. 1 and Table 1 are:

[G1] fit-for-purpose water use, which may be regulated by state or federal governments or health agencies and affects which water sources [D1] and water uses [D4] can be combined in the design decisions sub-component. It may also guide which design decisions (for example, treatment) are appropriate. 
[G2] water source licenses, which may be regulated by local or state governments or the environmental protection agency, depending on the catchment size, and will affect the amount of water available from particular sources for allocation in long-term operations [O4].

[G3] environmental flows, which similarly to water source licenses may be regulated by local or state bodies depending on the size of the catchment and affect the amount of water available for allocations [O4].

[G4] the discount rate applied to operational costs and GHG emissions in life-cycle analysis [E1]. This is unlikely to be set by a government body and rather will be informed from outside the decision making team, generally by recommendations from economists.

[G5] climate and energy policy set by state and federal governments will affect the energy sources available now and in the future, therefore affecting GHG emission factors and any GHG objectives [P].

\section{Analysis component [ANL]}

The analysis component uses information from the options, infrastructure and government policy components to simulate the system and evaluate how it performs relative to the objectives and constraints. Within an optimization algorithm, the analysis component is used to assess multiple combinations of decision variables from the options component to determine how they perform. There are two sub-components within the analysis component; the simulation sub-component [S] and the evaluation sub-component $[\mathrm{E}]$. The simulation sub-component includes the modeling aspects of the problem and the key variables that are required to be output from the models in order to evaluate the system. Optimization objectives and constraints are defined in the evaluation sub-component, which also provides information to the optimization algorithm as to which of the potential solutions perform best.

\section{Simulation Sub-component [S]}

The simulation sub-component considers the type of simulation model that is most applicable to the particular system and problem, and specifies the key variables that need to be calculated in the model(s). The critical aspects of this sub-component as shown in Fig. 1 and Table 1 are:

[S1] the hydrologic simulator, which is required if rainfall scenarios need to be transformed to streamflow, typically for systems using natural catchment water or harvested stormwater.
[S2] the mass balance model, which may be required for systems that have multiple water sources with long-term allocation decisions, particularly if there are different rainfall and evaporation scenarios to be considered for the storages.

[S3] the WDS hydraulic simulator, which is required to analyze pump and pipe systems that transfer water between different storages and treatments and to consumers.

[S4] information on constraints, such as yield from a hydrologic model, environmental releases and system reliability from a mass balance model, and nodal pressures, pipe velocities, pump switches and tank levels from a hydraulic model.

[S5] the water levels in storages, which are important particularly when considering operational decisions, such as trigger levels, and for constraints, such as system reliability.

[S6] the power usage from any pumps or treatment facilities, which are important in informing the ongoing electrical energy costs as part of life-cycle economic costing. Generally a WDS hydraulic simulator is required to model detailed pump operations and therefore accurately estimate the pump power usage.

Each of the three types of models will require different simplifications or assumptions depending on the particular system. For example, mass balance modeling will generally only consider one pump operating point so may not accurately calculate the pump power usage. When deciding which type of model to use for a particular problem, the user will need to consider the different simplifications, assumptions, advantages and disadvantages of each model. Trade-offs between accuracy of outputs and simulation run times need to be considered. For example, when optimizing both short- and longterm operations of a system, there is likely to be a tradeoff between using a hydraulic simulator for detailed hydraulic information and using a mass balance model for shorter run times. Most problems may ideally use elements from more than one type of model; however, using multiple models will increase computational complexity and run times. Wherever possible, the most applicable type of model should be selected and augmented with the required elements from other types of models. Depending on the particular system and optimization problem, there may be other key variables that need to be calculated in the simulation models. For optimization of pumping operations, which is the focus of the case studies in this paper, storage water levels and pump power usage are the most important. Existing hydrologic, mass balance and hydraulic simulators, for example, MUSIC, WATHNET and EPANET, have often 
been used in conjunction with optimization algorithms and should be taken advantage of where possible rather than creating individual simulators for different problems.

Information from the operation decisions subcomponent $[\mathrm{O}]$ will be input to the simulation subcomponent as the overall operating strategy for the system ([O3] and [O4]) will need to be modeled. Short-term operations are likely to be considered in a hydraulic simulator and long-term operations, including allocations, in a mass balance model. Parameter data on the physical components of the system from the water system infrastructure sub-component [W] are also required as inputs for this sub-component. Constraint information is provided to the evaluation sub-component to compare the systems performance against specified requirements. Energy usage is used to calculate objective functions such as life-cycle economic costs and life-cycle GHG emissions. Simulating systems prior to optimization is an important step to help inform the formulation of the optimization problem and provide a check that results from the optimization are reasonable.

\section{Evaluation Sub-component [E]}

The purpose of the evaluation sub-component is to compare the performance of each of the potential solutions to the objectives and constraints of the problem. The critical aspects of this sub-component as shown in Fig. 1 and Table 1 are:

[E1] the specific objective(s) to be considered in the optimization; typically, minimizing life-cycle economic cost is a primary objective (or a component of that such as construction cost or operational cost individually). Other possible objectives include minimizing spills from reservoirs and other storages, minimizing life-cycle GHG emissions (or a component of that such as embodied energy from construction or operational emissions), minimizing supplemental potable water supply (in systems using non-potable sources), maximizing water quality, maximizing reliability and minimizing environmental impact.

[E2] the objective function(s) to be optimized; multiple objectives may be evaluated as individual functions in a multi-objective optimization algorithm or combined into a single function for use in a single objective optimization algorithm. It is important to consider how each objective should be formulated, for example, when optimizing short-term pump operations to minimize ongoing costs, the objective function may be evaluated in terms of cost per volume of water pumped, as this will take into account the amount of water delivered to consumers. Reliability of a system may be formulated in different ways, for example minimizing the time spent with water restrictions applied or minimizing the time spent below a certain storage level. Some objectives may be more difficult to quantify, such as minimizing environmental impact, so more specific objectives may be required, for example, maximizing environmental flow or minimizing the change in a water body's natural hydrological regime. Simplifications and assumptions may be required to formulate some objectives as mathematical functions. When performing multi-objective optimization, trade-offs between the different objectives should be considered by the development of Pareto fronts, allowing the decision maker to determine which Pareto optimal solution best fits their needs (see examples in Wu et al. 2010a, b, 2012a, b, 2013).

[E3] the specific constraints to be considered as described in [S4].

[E4] the evaluation of the constraints compared to the limits set by the user; maximum and/or minimum values for each constraint need to be specified. Some constraints may be flexible, for example, if an environmental flow is set by a regulator, the operator could consider increasing the set environmental flow as a decision variable in the optimization. There are several different ways constraints can be incorporated into the optimization algorithm. Penalty functions are often used for single-objective problems. They add value (often a monetary amount) to the objective function in a minimization problem and remove value from the objective function in a maximization problem based on the magnitude of the constraint violation, therefore making solutions that violate constraints less desirable (Nicklow et al. 2010). Care must be taken when formulating penalty functions to keep solutions that only slightly violate constraints in consideration during the optimization process, while ensuring the feasibility of the final optimal solutions. For multi-objective problems, a constraint-handling technique that will ensure feasible solutions are retained in preference to infeasible solution is often employed. An example of this is the constraint tournament selection procedure introduced by Deb et al. (2002).

Information about the objectives is received from the simulation sub-component $[\mathrm{S}]$ and from the calculation of construction, maintenance and electrical energy costs based on the water system infrastructure sub- 
component $[\mathrm{W}]$ and simulation sub-component. A discount rate for costs or GHG emissions may be set in the government policy sub-component [G] which will impact the ongoing costs and emissions in a life-cycle analysis. The discount rate may be informed by economists, such as the Stern review which recommends low discount rates for projects that lead to the production of GHG emissions (Stern 2006). Information about the performance of each potential solution in relation to the objectives and constraints is provided to the optimization algorithm in order to find the best solutions.

\section{Optimization algorithm [OA]}

The optimization algorithm is used to determine which solution(s), out of many potential solutions to the problem, performs best in relation to the objective function(s). The procedure used to set up the optimization will depend on the type of algorithm chosen; however, the first step is generally to define the decision variables, objectives and constraints of the problem. This will then guide what aspects of the system need to be modeled and what data is required in order to take into account all of the decision variables and that will provide information for all of the objectives and constraints. Multiple potential solutions to the problem form the 'solution space' and the optimization algorithm guides the search of this solution space towards the global optimum. The size of the solution space depends on the number of decision variables and number of choices available for those decision variables. More complex problems are often described as having a more 'rugged' solution space, meaning the optimization algorithm is more likely to get trapped in local optima and will have more difficulty finding the global optimum. When a single objective optimization algorithm is used, one optimal solution will be found, while in multiobjective optimization, a Pareto front will be developed with multiple solutions representing different trade-offs between the objectives.

Most optimization algorithms have parameters that need to be defined by the user, such as the number of generations or iterations and the population size in evolutionary algorithms. Although the choice of these parameters does not influence the components shown in Fig. 1, they have an effect on the optimal solutions found by the algorithm. In general, the most effective set of parameter values to use will vary between different optimization problems and the size of the solution space can only give some indication of what parameter values to use. In fact, multiple parameter sets should be tested in order to find the most appropriate values for the specific problem. Ideally, the chosen parameter set should find the same optimal solution regardless of the starting point or initial solution(s) for the optimization. Dandy et al. (1996) presented an improved genetic algorithm formulation for optimization of WDS design. Five different parameter sets were trialed on both their improved genetic algorithm and a comparatively simple genetic algorithm. They acknowledged that parameter selection does require some judgement on the part of the user, however, they found their optimization results to be relatively insensitive to the parameter choice, particularly for the improved genetic algorithm. As well as the effect of various parameter values, different optimization algorithms will be more suited to different problems. This issue has been addressed by the development of hybrid algorithms, such as AMALGAM (a multi-algorithm, genetically adaptive multiobjective approach proposed by Vrugt and Robinson (2007)), which combines several different optimization algorithms to improve search efficiency. These hybrid algorithms also have the benefit of requiring little to no parameter specification by the user.

\section{Sensitivity analysis}

As identified in Table 1, values of some input parameters (for example, describing the network or water demand loadings) are uncertain or subject to change in the future. Sensitivity analysis can be performed to account for a wide range of possible future conditions when optimizing and simulating systems. Variation of a particular parameter may result in different Pareto fronts (in multiobjective optimization) or different optimal solutions (in single objective optimization), as seen in Wu et al. (2010b) when they considered variations in discount rates. These various Pareto fronts or optimal solutions along with the various parameter values that produced them can then be provided to the decision maker. Sensitivity analysis will also help to identify if there are any uncertain parameters that do not affect the optimal results. Robustness of the optimized solutions can also be explored a-posteriori: in general, solutions that perform well for many different possible conditions are more desirable from the decision makers' point of view. Climate change provides an additional source of uncertainty for the parameters identified in Table 1 - detailed discussion of this is omitted from Sections 'Demand,' 'Rainfall and streamflow,' 'Electricity and GHG emissions' and 'Discount rate' as it is covered in Section 'Climate change'.

\section{Demand}

In some applications, such as irrigation and agriculture, the demand rate and pattern may be deterministic [O1], either the water supplier has control over the consumption, or may be able to work with those who do to determine an optimal demand schedule. For other applications, such as domestic, commercial and industrial, the demand rate and pattern depends on the consumption of water by multiple individual users 
[D4, W13, W14, W15], and therefore has greater uncertainty. Historical consumption can provide some level of assurance as to how water may be used in the future, at least on an aggregated scale. Diurnal, weekly and seasonal demand variations need to be considered. In the future, factors such as climate change, population growth and water saving initiatives will affect how water is consumed and therefore impact demand rates and patterns. Emergency conditions and system failure are by their nature unpredictable and this should be taken into account when designing and operating WDSs.

An example of how demand uncertainty can be considered in the optimization of WDS design is the study by Basupi and Kapelan (2015). The demand at each time step was based on a normal distribution with a gradually increasing mean (based on deterministic demand forecasts) and an increasing standard deviation. Monte Carlo or Latin Hypercube simulation was included in their methodology to consider multiple demand scenarios. Each solution in the Pareto front was also further analyzed against three demand projections - average, optimistic (low overall demand) and pessimistic (high overall demand). Their results demonstrated the value of flexible WDS design over deterministic approaches when considering uncertainty.

\section{Rainfall and streamflow}

Rainfall and streamflow inputs [W1] may be required for systems using natural catchment water, harvested stormwater or imported water, and they are often treated with higher uncertainty than demands (Seifi and Hipel 2001; Reis et al. 2005). Within the current climate, there may be multiple realizations of possible rainfall and streamflow series (for example dry or wet years). Beh et al. (2015) considered rainfall, as well as population and temperature, as uncertain variables in their optimal sequencing methodology for water supply system augmentation. They considered both climate and hydrologic variability: seven possible future climate scenarios provided different forecasted rainfall reductions, and within each of these seven scenarios, 20 stochastic replicates of the rainfall sequence were produced. Different Pareto fronts were produced for each climate scenario, with the more severe scenarios finding solutions that required greater system augmentation and therefore had higher costs and GHG emissions. The robustness of each Pareto solution was calculated based on the average reliability and vulnerability of the solution over the 20 rainfall sequences for the particular climate scenario.

\section{Electricity and GHG emissions}

Power source(s) [P1], electricity tariffs and costs [P2] and GHG emission factors [P3] will generally be known for the present time, however, it may not be clear how they will change in the future. The mix of power sources changes naturally over time, as different power plants are built or decommissioned. This change in power source types over time, as well as technical advancements will affect the cost and GHG emissions associated with electrical energy generation. The electricity market and economic factors will also affect the cost of electrical energy over time. Changes in electricity and GHG emissions can be an important factor to consider during an optimization problem, as shown in the following examples. Blinco et al. (2014) studied the optimization of pump operations in WDSs in relation to the minimization of GHG emissions and the use of different power source scenarios, showing that optimal tank trigger levels can be influenced by the variation in emission factors. Wu et al. (2012a) considered three different electricity tariff scenarios, which increased over time, and three different GHG emission factor scenarios, which decreased over time, in the optimization of WDS design. The different electricity tariff and emission factor scenarios affected the solutions found in the Pareto front and their overall costs and GHG emissions.

\section{Discount rate}

A discount rate [G4] may be used in life-cycle analysis for both ongoing economic costs and ongoing GHG emissions. In practice, discount rates on economic costs vary significantly between different organizations, generally from 2 to 10\% (Rambaud and Torrecillas 2005), while many water utilities use discount rates in the range of 6 to $8 \%$ (Wu et al. 2010a). When selecting discount rates, consideration should be given to whether both economic costs and GHG emissions are discounted, if they have the same discount rate, and if intergenerational equity is taken into account using social discount rates. Various social discount rates have been proposed for discounting ongoing costs; the Intergovernmental Panel on Climate Change (IPCC) adopted a zero discount rate over a period of 100 years, after which no consideration for future costs or benefits is given (Fearnside 2002), other suggestions include 1.4\% (Stern 2006) for projects that are impacted by climate change, 2-4\% (Weitzman 2007) and a time declining rate (Gollier and Weitzman 2010). Wu et al. (2010b) gave an example of a sensitivity analysis of discount rates in the optimization of WDS design for minimization of costs and GHG emissions. Discount rates of 0, 1.4, 2, 4, 6, 8\% and a time declining rate were applied to the economic costs, with GHG emissions either not discounted at all, or discounted at the same rate as costs. They found that the different discount rate scenarios produced different Pareto fronts; when GHG emissions were discounted, the solutions tended to have lower capital costs and higher operating emissions. 


\section{Climate change}

Management of water resources in the developed world has been based on an assumption of stationarity - that is, 'that natural systems fluctuate within an unchanging envelope of variability' (Milly et al. 2008). The effects of human-induced climate change make this assumption no longer valid (Milly et al. 2008), and introduce additional sources of uncertainty for many parameters. Uncertainty introduced by climate change is twofold - firstly, the impacts of climate change increase the uncertainty of future weather conditions; and secondly, our response to the threat of climate change and the types of adaption methods that will be utilized in the future are uncertain. Climate change affects the magnitude and temporal and spatial distribution of rainfall, temperature and other environmental factors, thus the possible rainfall and streamflow series to consider for the future will likely be different to the present. Changes to temperature and other environmental factors will also affect the hydrology of natural and urban catchments and therefore change how rainfall will transform to runoff or streamflow. Climate change impacts will also affect how people consume water, for example, higher temperatures and lower rainfall may drive people to water their gardens more. In order to simulate future climate conditions, general circulation models (GCMs) are often used in conjunction with future emissions scenarios. According to Mpelasoka and Chiew (2009), 'GCMs are the best tools available for simulating global and regional climate systems', however, the information provided is generally too coarse for applications to catchment runoff, and therefore some kind of downscaling is required. The modeling uncertainty of both the GCMs and downscaling methods increases the uncertainty of future climate scenarios (Paton et al. 2013). In 2000, the IPCC introduced several emissions scenarios (termed SRES scenarios) projecting future global GHG emissions (IPCC 2000). The various scenarios are based on different assumptions of the mix of energy generating technologies (fossil fuel or non-fossil fuel dominant) and population, economic and technological growth (IPCC 2007).

The extent to which we can reduce our GHG emissions will affect the magnitude of climate change impacts on rainfall and temperature. With the growing concerns of climate change and sustainability, renewable sources such as solar and wind will become more prevalent and replace fossil fuel sources such as coal and gas. This may affect electricity pricing and GHG emissions from power generation. Multiple future power source scenarios assuming different levels of climate change mitigation may need to be considered. Other climate change adaption strategies include economic incentives such as carbon taxes and cap and trade systems, which may affect economic analysis of WDSs. As discussed in Section 'Discount rate', when climate change and intergenerational equity are considered, social discount rates of $0,1.4,2-4 \%$ and time declining rates have been proposed.

Paton et al. (2013) analyzed the sources of uncertainty relating to climate change and their impact on water supply security. They considered 19 different scenarios with different combinations of six SRES scenarios, seven GCMs and six demand projections, as well as 1000 stochastic rainfall replicates. They found that the impact of the different sources of uncertainty on the optimal solutions varied over the 40 -year planning period, with some having a greater effect in the short-term and others a greater effect in the long-term. Roshani and Filion (2014) investigated the impact that different climate change abatement strategies have on water main rehabilitation. They consider six carbon abatement strategies with different combinations of two discount rates (1.4 and 8\%) and three carbon tax scenarios (no tax, 'fast and deep', and 'slow and shallow'). Using a low discount rate and implementing a carbon tax encouraged the optimization algorithm to find solutions that invested in rehabilitation early, to reduce the cost of continuing leaks, pipe repair, energy use and GHG emissions.

\section{Case studies}

The utility of the framework described in the previous sections will now be explored by two different case studies that have different water sources and many variables that need to be considered. These case studies are provided as an example of how the framework could be applied to optimize system operations. The first case study is a managed aquifer recharge (MAR) system that harvests stormwater from an urban creek for irrigation of reserves and sporting fields. This case study demonstrates the importance of analyzing the system by simulation prior to optimization in order to formulate the optimization problem. The second case study is a water supply system in a rural town that supplies potable water from multiple alternative water sources. This system is optimized for minimization of energy use of the many pumps used to transfer water from the various sources.

\section{Ridge Park managed aquifer recharge - case study 1}

Ridge Park is located in the Adelaide metropolitan area in South Australia, within the City of Unley local government area. The scheme supplies harvested stormwater to sports fields and recreational reserves in the local area for non-potable irrigation use. The scheme is designed to harvest up to $60 \mathrm{ML}$ of stormwater per year, which occurs over the winter, while in summer the harvested water is used for irrigation. During winter, stormwater from Glen Osmond Creek, an urban waterway, is collected in the Harvest Pond created by a dam on the creek (Fig. 2). Water is then pumped to the Bioretention 


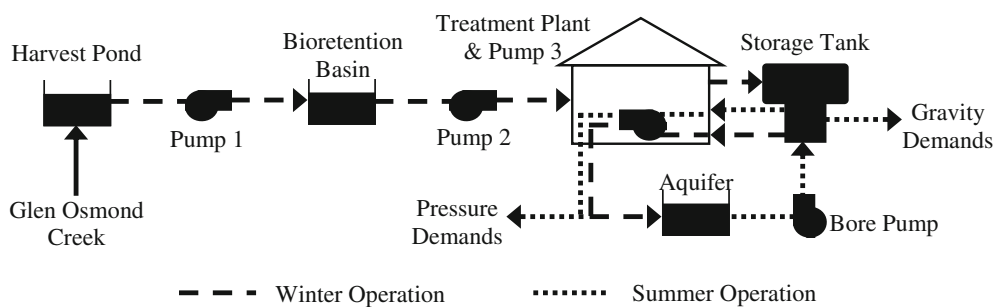

Fig. 2 Ridge Park managed aquifer recharge system process schematic

Basin which provides some treatment, and then pumped to a small treatment plant that includes UV and filtration. Once the water has been adequately treated, it is stored in an above ground tank next to the treatment plant and final pump station. From the Storage Tank, water is injected into an artesian, fractured rock aquifer for long term storage. In summer, when no water is being harvested, water is extracted from the Aquifer and to the Storage Tank, before being pumped or gravity-fed to irrigation points. The Ridge Park Reserve is irrigated by a pressurized irrigation line, as it is at higher elevation than the Storage Tank. Fraser Reserve is also connected to the pressurized system to ensure adequate pressures for irrigation. In total, the pressurized system supplies almost $15 \mathrm{ML}$ of water per year. The remaining seven reserves are on a gravity-fed line which supplies a total demand of roughly $35 \mathrm{ML}$ per year. The layout and details of the system are given in Fig. 3. For more detailed data on this case study, please see the Additional files 1, 2, 3 and 4 .

For existing systems, simulation analysis of the current operation is an important first step in formulating the optimization problem. Results of current operational simulations can highlight areas for improvement that can then be focused on in the optimization. The operation of the Ridge Park stormwater harvesting system was split between winter and summer operations and both were simulated in EPANET to determine current pump operational costs. Trigger levels (related to volumes in the three storages as shown in Table 2) control when the pumps in the Winter Harvesting and Injection system turn on and off (Table 2). The Bore Pump is also

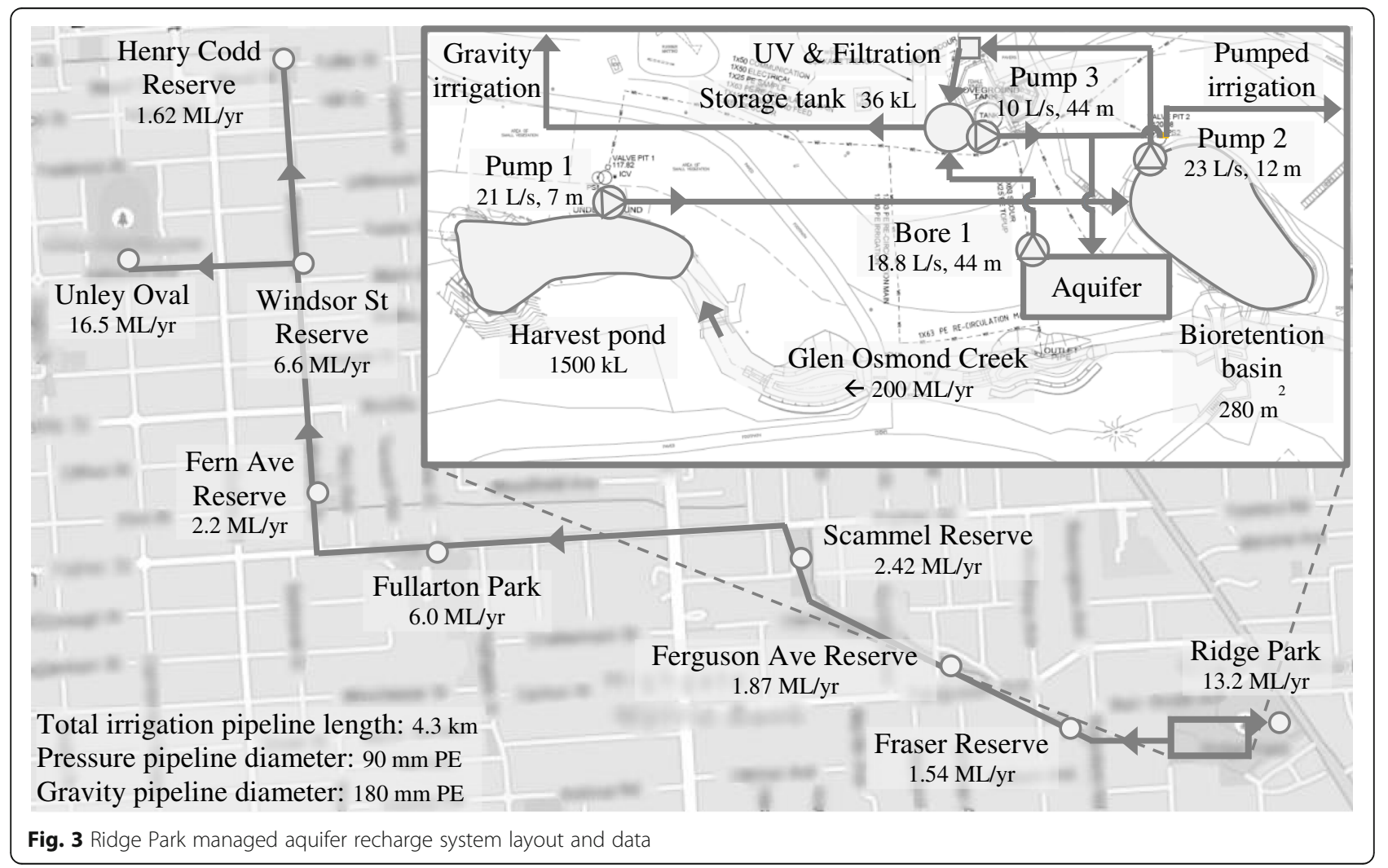


Table 2 Trigger levels for the Ridge Park system

\begin{tabular}{llclll}
\hline \multirow{2}{*}{$\begin{array}{l}\text { Storage and trigger level } \\
\text { type }\end{array}$} & \multicolumn{2}{l}{ Current setpoint } & \multirow{2}{l}{$\begin{array}{l}\text { Start } \\
\text { pump }\end{array}$} & $\begin{array}{l}\text { Stop } \\
\text { pump }\end{array}$ \\
\cline { 2 - 4 } & Volume (\%) & Level $(\mathrm{m})$ & & \\
\hline Harvest Pond High Level & 80 & 1.6 & 1 & - \\
Harvest Pond Low Level & 50 & 1.0 & - & 1 \\
Biofiltration Basin High Level & 90 & 0.80 & 2 & 1 \\
Biofiltration Basin Low Level & 50 & 0.59 & - & 2 \\
Storage Tank High Level & 90 & 2.25 & 3 & 2 , Bore \\
Storage Tank Low Level & 70 & 1.75 & Bore & 3 \\
\hline
\end{tabular}

controlled by trigger levels in the Storage Tank. During summer, Pump 3 is controlled by the irrigation demands, which are on a schedule so that different reserves are irrigated on different nights (Table 3). Pump 3 is a VSP and is operated at $80 \%$ of full speed for injection (such that the flow is less than the $7 \mathrm{~L} / \mathrm{s}$ maximum for injection) and $75 \%$ of full speed for irrigation (such that the target pressure downstream of the pump is achieved at the expected demand rates). Both systems were simulated for a period of 1 week in EPANET, with a 15 min hydraulic time step and 5 min reporting time step. Several week-long streamflow series for the available flow in Glen Osmond Creek at a daily resolution were used in the harvesting and injection model (Fig. 4). A peak/off-peak electricity price tariff applied to the entire system; a peak price of $25.53 \mathrm{c} / \mathrm{kWh}$ was applied from 7 am to $9 \mathrm{pm}$ on weekdays, and an off-peak price of $15.26 \mathrm{c} / \mathrm{kWh}$ was applied over night and on weekends (tariff pattern and simulations started on a Sunday).

\section{Winter harvesting and injection system current pumping operation results}

When there was adequate water available, such as in Streamflow Series 1,4 and 5, the volume of water injected into the aquifer (by Pump 3) was a little over 3 ML per week (Table 4). This was significantly less than the volume available, which reflects the limited flow rate of Pump 3 (7 L/s for injection to the aquifer), as well as the water that would be lost to overflow when the inflow rate is greater than the flow rate of Pump 1 (approximately $22 \mathrm{~L} / \mathrm{s}$ ). The total pump energy cost estimate for the harvesting and injection system ranged from $\$ 163$ to $\$ 267$ per week, with an average of \$235 per week. Pump 1 was the most cost-effective to run, while Pump 3 was the most expensive. Pumps 1 and 2 operated at similar times throughout the day, however, Pump 2 has much lower efficiencies, which increased its energy use. Pump 3 operated at a lower flow rate but much higher head than Pumps 1 and 2, and was more likely to be switched on for the entire day, which contributed to its higher cost of operation. Pumps 1 and 2 turned on and off very frequently, and operated at a much higher flow rate than Pump 3 (Fig. 5). The flow rate of Pump 3 in Fig. 5(c) reduced over the week as the headloss through the bore increased from assumed clogging of the bore. As the storages are relatively small, in particular the storage tank, it did not take long for them to be filled and emptied (Fig. 6), which contributed to the frequent pump switches. The current trigger levels in the Storage Tank are very close together (70 and 90\% volume) as a result of possible pump priming issues that occurred during the commissioning of the system. These close together trigger levels also contributed to the short fill and empty times.

\section{Summer extraction and injection system current pumping operation results}

Simulation of the irrigation system gave a total weekly pump energy cost of $\$ 90$ (Table 5). The Bore Pump was more expensive overall, however, cost less per megaliter than Pump 3. This occurred because while the Bore Pump has a greater efficiency than Pump 3, it also has a higher flow and head, which increased the energy consumption. The higher volume pumped from the bore contributed to a lower cost rate than Pump 3. All of the pumping for this system occurred overnight (Fig. 7)

Table 3 Irrigation demand schedule for the Ridge Park system

\begin{tabular}{lcccc}
\hline Reserve & Demand rate $(\mathrm{L} / \mathrm{s})$ & Duration/day $(\mathrm{hr})$ & Start time & Irrigation days \\
\hline Ridge Park 1 & 3.53 & 8.33 & $9: 30$ PM & Mon \& Wed \\
Ridge Park 2 & 3.53 & 8.67 & $9: 30$ PM & Tues \& Thurs \\
Fraser Reserve & 1.41 & 5.83 & $9: 30$ PM & Mon \& Wed \\
Ferguson Ave Reserve & 2.00 & 5.00 & $9: 30$ PM & Tues \& Thurs \\
Scammell Reserve & 2.15 & 6.00 & $10: 00$ PM & Tues \& Thurs \\
Fullarton Park 1 & 3.85 & 1.67 & $10: 00$ PM & Mon \& Wed \\
Fullarton Park 2 & 3.85 & 6.67 & $10: 00$ PM & Tues \& Thurs \\
Fern Ave Reserve & 3.53 & 3.33 & $10: 00$ PM & Mon \& Wed \\
Windsor St Reserve & 2.20 & 8.00 & $8: 30$ PM & Tues \& Thurs \\
Henry Codd Reserve & 1.10 & 8.00 & $10: 00$ PM & Mon \& Wed \\
Unley Oval & 5.57 & 9.00 & S:00 PM & Sun, Mon \& Wed \\
\hline
\end{tabular}




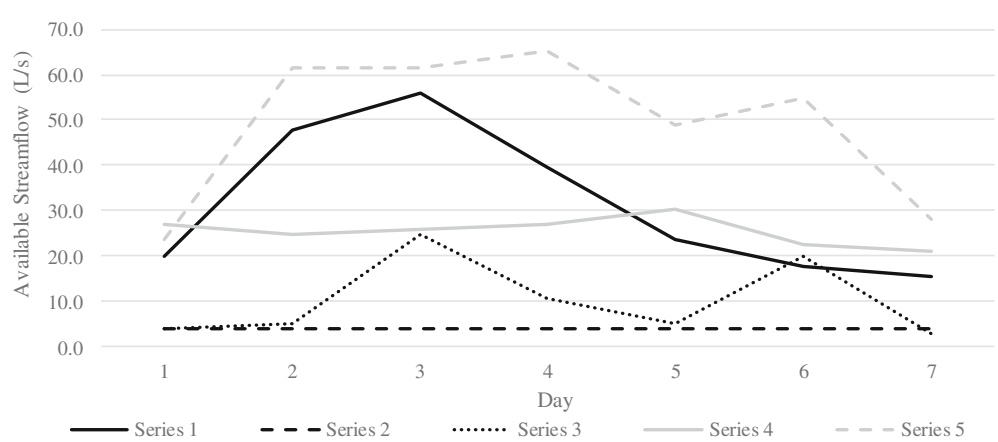

Fig. 4 Streamflow Series used for simulation of the winter harvesting and injection operation

when irrigation of all fields is allowed. The Bore Pump turned on and off very frequently when it was operating, again due to the small capacity of the Storage Tank which meant it did not take long for the pump to fill the operating volume (Fig. 8).

\section{Optimization formulation}

Initially, optimization of the Ridge Park system was considered to be an operational problem, however, results of the current operation simulation suggest that design decision variables need to be considered as well. Replacing Pumps 1 and 2 with models that would operate at much lower flow rates (to reduce the headlosses) and increasing the size of the Storage Tank will be considered along with operational decision variables (Table 6). These design decisions would aim to counter-act mismatched pump rates (Pumps 1 and 2 operating at a much higher rate than Pump 3) and small storage volumes that lead to frequent pump switches. Short-term operational decisions include trigger levels in the Harvest Pond, Bioretention Basin and Storage Tank that will govern when pumps are turned on and off, a schedule for irrigation (that is, which reserves will be irrigated at which times), and VSP multipliers for Pump 3. In the current operation, VSP multipliers for Pump 3 were selected to ensure the required flow rate (for injection) and pressure (for irrigation) were achieved. With different levels in

Table 4 Current operation results for the winter harvest and injection system

\begin{tabular}{|c|c|c|c|c|c|c|}
\hline \multirow{2}{*}{$\begin{array}{l}\text { Streamflow } \\
\text { Series }\end{array}$} & \multirow{2}{*}{$\begin{array}{l}\text { Available } \\
\text { volume } \\
\text { (ML/wk) }\end{array}$} & \multicolumn{3}{|c|}{ Cost (c/kL) } & \multirow{2}{*}{$\begin{array}{l}\text { Volume } \\
\text { injected } \\
\text { (ML/wk) }\end{array}$} & \multirow{2}{*}{$\begin{array}{l}\text { Total } \\
\text { cost } \\
\text { (\$/wk) }\end{array}$} \\
\hline & & Pump 1 & Pump 2 & Pump 3 & & \\
\hline 1 & 19.0 & 0.64 & 2.28 & 5.49 & 3.14 & 267 \\
\hline 2 & 2.29 & 0.68 & 2.32 & 6.19 & 1.76 & 163 \\
\hline 3 & 6.19 & 0.69 & 2.23 & 5.87 & 2.44 & 222 \\
\hline 4 & 15.4 & 0.64 & 2.24 & 5.46 & 3.18 & 258 \\
\hline 5 & 29.7 & 0.63 & 2.25 & 5.47 & 3.16 & 264 \\
\hline Average & 14.5 & 0.66 & 2.26 & 5.70 & 2.74 & 235 \\
\hline
\end{tabular}

the Storage Tank considered, the VSP multipliers for Pump 3 can be altered, especially if efficiency is improved. If the pump priming issues discussed earlier were to be resolved, trigger levels that utilize the full height of the Storage Tank (rather than the 20\% range in water elevation that is currently used) would be considered in the optimization. There are also long-term decision variables deciding when to switch between summer and winter operation and vice versa (Table 6). As the scheme injects to and extracts from the aquifer through the same bore, it is not possible to frequently switch between injecting and extracting water, therefore there will be only two switch times per year; one going into winter operation and one going into summer operation. The decision variables presented in Table 6 may all be considered together in an optimization problem, however, they could also be analyzed prior to optimization in a simulation sensitivity analysis. Simulating the system initially with the different pump models and storage tank sizes could help to decide if these actions are worthwhile considering in an optimization formulation. Engineering judgement may be sufficient to determine which pump model(s) would be best to replace Pumps 1 and 2, and therefore reduce the size of the optimization problem.

Constraints on the system include an environmental flow for Glen Osmond Creek, an extraction limit from the Aquifer and meeting the weekly irrigation volumes for each reserve in the summer (Table 7). If there was not enough water harvested over the winter to supply the summer demands, a potable back-up supply is available at a cost. The main objective for this case study is to minimize the pump energy cost; there is also a secondary objective of minimizing the number of pump switches. To create an incentive for the optimization to find solutions that harvest more water, the cost objective includes the energy cost for the harvesting and distribution operation as well as the cost of purchasing potable water if the harvested volume is not enough to supply demand. The objective function is formulated as the cost per volume of water harvested as another means to ensure 


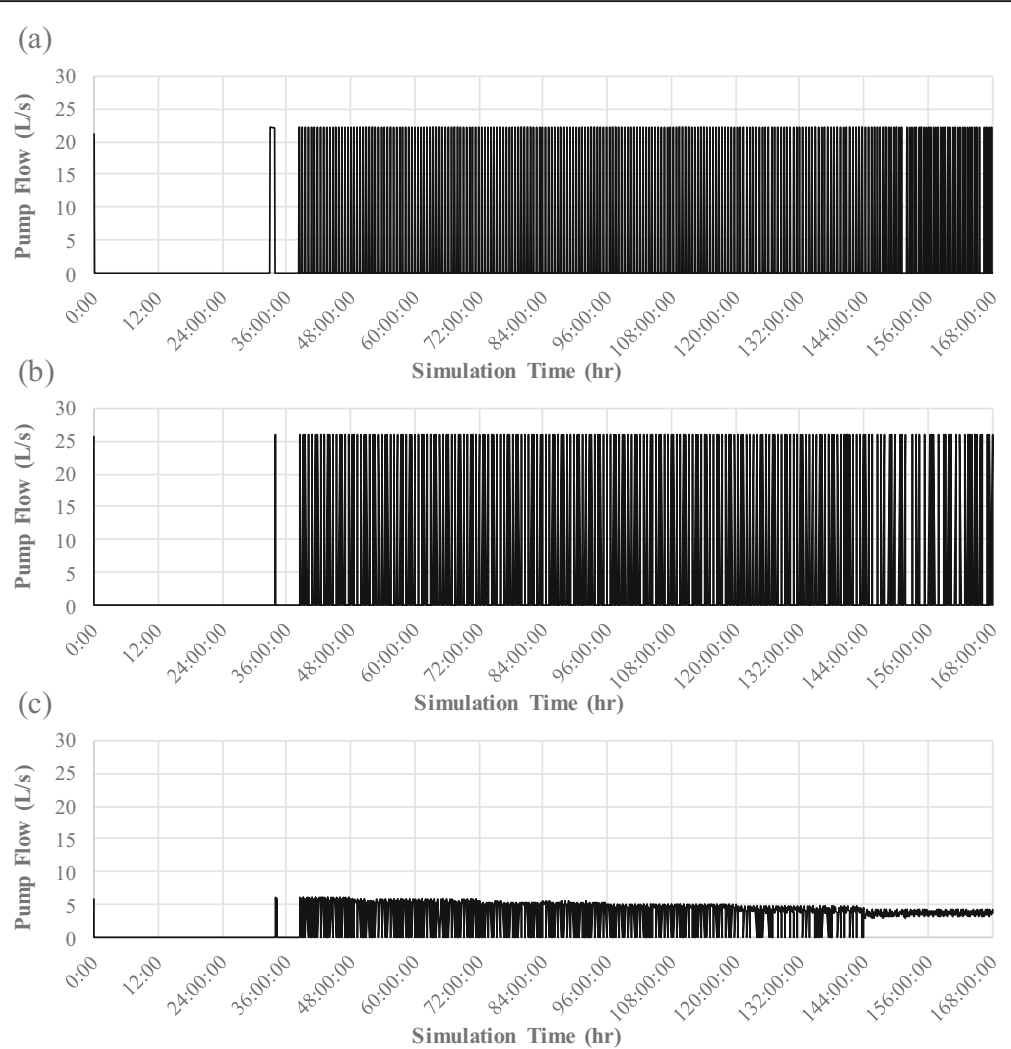

Fig. 5 Pump flows for Streamflow Series 2 for a Pump 1, b Pump 2 and c Pump 3 for a one week EPANET simulation

enough water is harvested from the system during winter to supply summer irrigation. During the conceptualization and design of this scheme, regulations from the South Australian Environmental Protection Authority (EPA), the Department for Environment, Water and Natural Resources (DEWNR) and the Department of Health (DoH) were considered. A license to recharge water into the aquifer was required from the EPA, while the DEWNR regulates how much water can be extracted from MAR schemes. DoH regulations informed the level of treatment implemented and the irrigation practices, which must limit the risk of public exposure.

\section{Orange integrated supply system - case study 2}

Orange is a rural town roughly $250 \mathrm{~km}$ west of Sydney in the state of New South Wales, Australia. The water supply system serves a population of around 36,800 people with an average annual demand of approximately 5,400 ML. The majority of water supply is from the local surface water catchment, which culminates in the roughly 19,000 ML Suma Park reservoir (Fig. 9). Australia experienced severe drought between 2000 and 2010, and Orange was one of the hardest hit areas in New South Wales. Even with severe water restrictions almost halving the town's demand, Orange had less

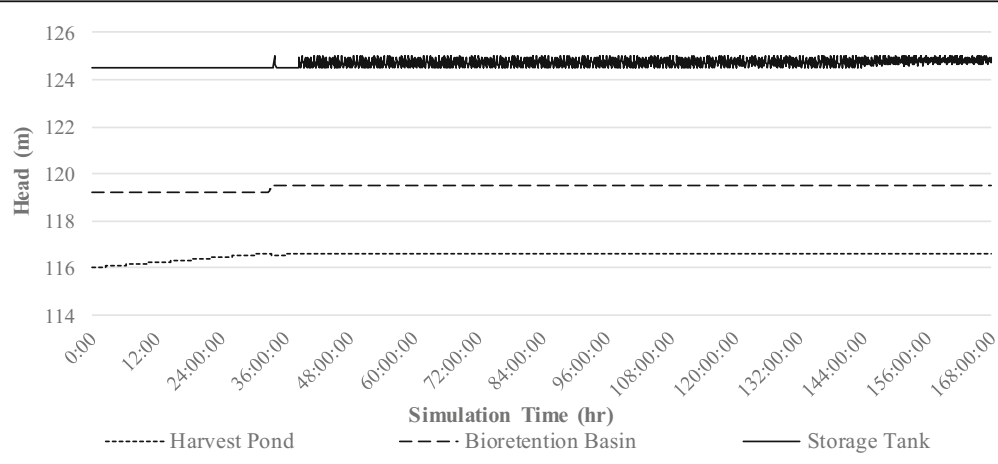

Fig. 6 Storage levels for Streamflow Series 2 
Table 5 Current operation results for the summer extraction and irrigation system

\begin{tabular}{lll}
\hline Pump & Volume $(\mathrm{ML} / \mathrm{wk})$ & Cost $(\mathrm{c} / \mathrm{kL})$ \\
\hline Bore Pump & 1.93 & 3.52 \\
Pump 3 & 0.57 & 3.97 \\
Total & & $\$ 90.3 /$ week \\
\hline
\end{tabular}

than two years of water supply heading into summer of 2009 and was relying only on surface water catchments (Montgomery Watson Harza, 2011). This prompted the Orange City Council to diversify their water supply, and they therefore developed two stormwater harvesting schemes and a long pipeline from an adjacent catchment, as well as re-opening several groundwater bores. Figure 2 shows a schematic process diagram of the system, which is described below, and Fig. 3 shows the layout (note that the 'Shearing Shed' Bore and 'Bore 5 ' in Fig. 2 are grouped as the 'Clifton Grove' Bores in Fig. 10). For more detailed data on this case study, please see the Additional files 1, 2, 3 and 4.

Water from the Ploughman's Creek Stormwater Scheme is treated through a series of wetlands, and then combined with water from the Blackman's Swamp Creek Stormwater Scheme. After treatment, this water can be used to top up Suma Park reservoir. Due to the severely low water supply levels during the drought, Emergency Authorization was initially given, and Council subsequently sought approval for use of the stormwater schemes on a permanent basis. Continuous water quality monitoring is undertaken to meet regulations of the Office for Water, the New South Wales Environmental Protection Authority and the Ministry of Health. To the authors' knowledge, this is the only system in Australia that has been approved to use harvested stormwater for potable supply. In order to use harvested stormwater for potable supply, the Council had to meet requirements of the Office for Water. The Macquarie pipeline transfers water from the adjacent Macquarie River catchment to Suma Park reservoir. It is $38 \mathrm{~km}$ long and requires more than $600 \mathrm{~m}$ of pumping head. Each of the three pumping stations has two pumps operating in parallel. Water from the groundwater bores is pumped first to balancing storages and then to Suma Park reservoir, with a combined licensed volume of 462 ML per year. Water from all of the sources is combined in Suma Park reservoir and treated at a water treatment plant before being delivered to consumers.

The Orange City Council is interested in optimizing the operation of this while delivering a secure yield from Suma Park Dam. In addition to the primary objective of minimizing energy cost, there are objectives of minimization of spill from Suma Park reservoir, minimization of (perceived) environmental impact, maximization of (perceived) water quality, and minimization of energy use. The Council has an explicit objective to minimize spill to ensure water and energy are not wasted by pumping from one of the three alternative sources to fill up Suma Park reservoir just before a rainfall event that would supply water from the natural catchment at no cost or energy output. As this system supplies potable demands, it is undesirable to apply water restrictions to consumers, thus minimizing time spent in restrictions is important. Objectives for the perceived environmental impact and water quality will be formulated as a preference ranking between the different sources based on community views of which sources are better for the environment and water quality. The constraints of the problem include environmental flows for the Macquarie River (downstream of the pumping station offtake point) and stormwater schemes, a water source license for the Macquarie River and extraction limits on the groundwater bores (Table 8).

\section{Energy optimization formulation}

In this section, the developed framework is applied to the Orange case study to help set up the optimization procedure and identify the components and data to be modeled. Note that the model has been built taking into account all possible objectives of the system, however, the example of results presented here will focus on the minimization of energy consumption.

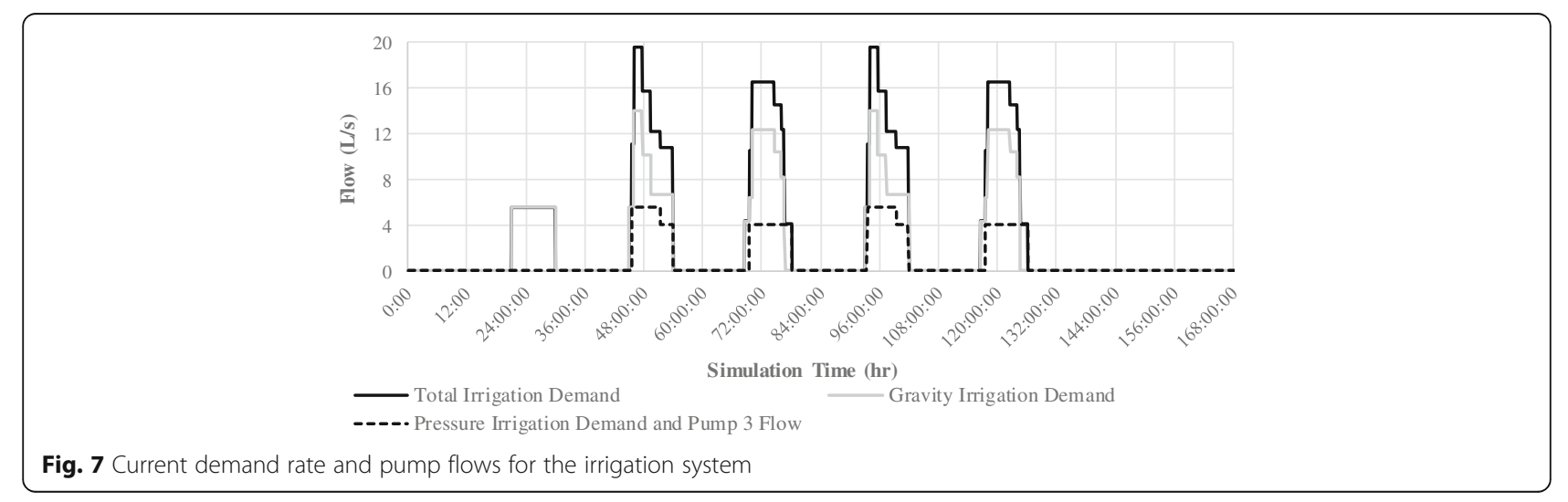




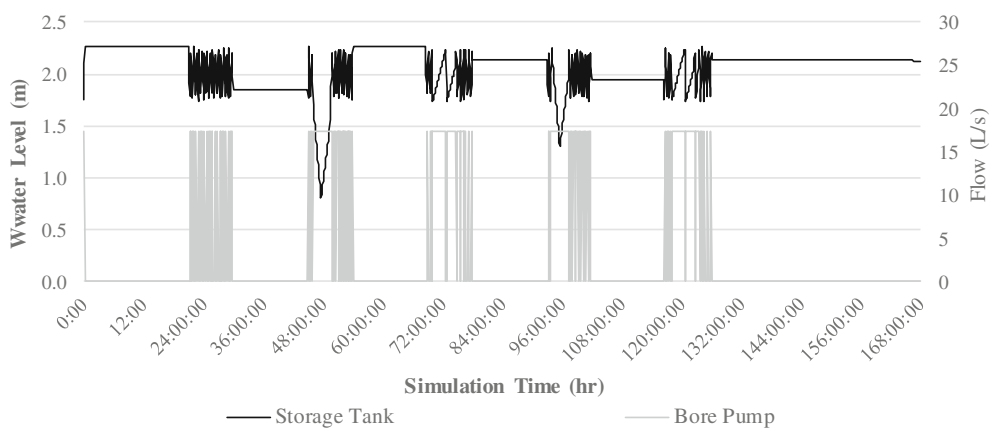

Fig. 8 Storage tank level and bore pump flow for the summer extraction and irrigation system

As all components of the system have already been constructed and considered sufficient for the operation of the system, there are no design decisions to consider, only operating decisions. For this case study, operating decisions consist of trigger levels in the various storages. These types of decision variables are chosen considering the control system available at each pump station (based on storage levels and not on time of the day) and the fact that the controls have to be defined for an operational horizon of 1 year or longer. As all of the

Table 6 Possible decision variables for the Ridge Park MAR scheme Short-term winter harvesting and injection operation

$\begin{array}{ll}\text { Pump } 1 \text { Off } & \begin{array}{l}\text { Harvest Pond Level Low } \\ \text { Bioretention Basin Level High } \\ \text { Pump } 1 \text { On }\end{array} \\ \text { Pump 2 Off } & \text { Biorest Pond Level High } \\ & \text { Storage Tank Level High } \\ \text { Pump 2 On } & \text { Bioretention Basin Level High } \\ \text { Pump 3 Off } & \text { Storage Tank Level Low } \\ \text { Pump 3 On } & \text { Storage Tank Level High } \\ \text { Pump } 3 \text { Speed } & \text { Storage Tank Level }\end{array}$

Short-term summer extraction and irrigation operation

\begin{tabular}{|c|c|}
\hline Bore Pump Off & Storage Tank Level High \\
\hline Bore Pump On & Storage Tank Level Low \\
\hline \multirow[t]{2}{*}{ Irrigation Schedule } & Days of Irrigation at each Reserve \\
\hline & $\begin{array}{l}\text { Start Time of Irrigation at each } \\
\text { Reserve }\end{array}$ \\
\hline Pump 3 Speed & Required Demand Rate \\
\hline \multicolumn{2}{|l|}{ ong-term operations } \\
\hline Day to Switch Between & Summer to Winter \\
\hline Seasonal Operational Regimes & Winter to Summer \\
\hline \multicolumn{2}{|l|}{ system Design } \\
\hline Storage Tank Size & $\begin{array}{l}\text { Doubled, } 5 \text { times, } 10 \text { times current } \\
\text { size }\end{array}$ \\
\hline Pumps 1 and 2 & $\begin{array}{l}\text { Selection of pump curves with lower } \\
\text { operating rates }\end{array}$ \\
\hline
\end{tabular}

pump stations have two or more pumps arranged in parallel, having different trigger level values may have a large impact on the operating point of the pumps and consequently their energy consumption. It is also likely that different trigger levels will be chosen for peak and off-peak electricity tariff periods when they are included in a cost optimization. For this system a peak/ off-peak electricity tariff applies on weekdays, with weekends priced at the off-peak rate. A peak monthly electrical energy demand charge also applies to the Macquarie River pipeline pumping system. In order to assess the performance of different tank trigger levels, the infrastructure to be modeled includes the natural and urban catchments for the surface water and stormwater systems respectively, Suma Park reservoir, pipelines and pumps in the groundwater, Macquarie River and stormwater systems, and wetlands and storage ponds in the stormwater systems.

In general, the system could be modelled using hydrologic models, mass balance models, and/or hydraulic models. The choice of which model(s) will be used depends on the objectives and the processes to be modelled, on the available data and the computational times. In particular, hydrologic modeling is usually used to transform rainfall to runoff for the natural and urban catchments. For this case study, inflows inputs or approximate relationships between rain and flows were provided by previous studies by the Orange City Council. Hydraulic models are usually used for short term operations: pump energy costs can be computed accurately based on the hydraulic equations. Mass balance modeling is usually used for assessing the system in long term operations, as it can

Table 7 Possible constraints for the Ridge Park MAR scheme

\begin{tabular}{ll}
\hline Constraint & Value \\
\hline Glen Osmond Creek Environmental Flow & $>2 \mathrm{~L} / \mathrm{s}$ \\
Aquifer Extraction in Summer & $<80 \%$ of Injection Volume \\
Pressurized System Demands & $>15 \mathrm{ML} /$ year \\
Gravity System Demands & $>37 \mathrm{ML} /$ year \\
\hline
\end{tabular}




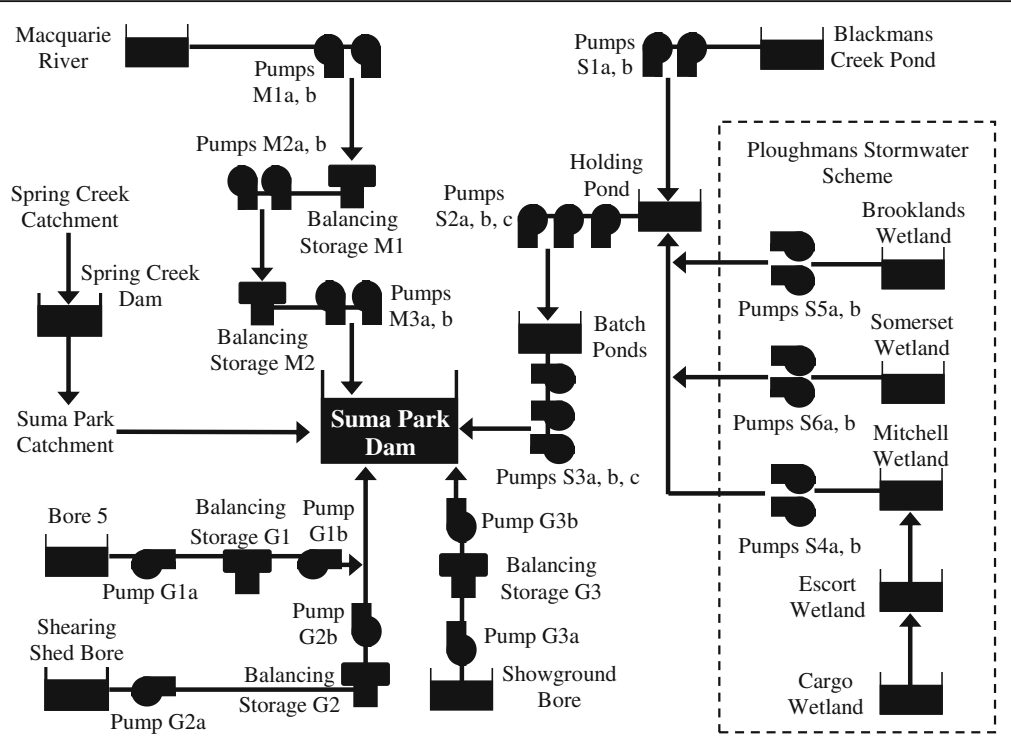

Fig. 9 Orange integrated supply system process schematic - inflow to Suma Park Dam

quickly compute the water available after evaporation and other losses in the system have occurred and after minimum environmental flows have been released. It cannot, however, take into account the non-linearity in the hydraulic equations and therefore assumptions need to be made in regard to the flow delivered by the pumps in the system. While hydraulic simulation would be most appropriate for the pumping stations in the system as they have multiple pumps and sometimes have connected pipelines, mass balance models would need to be used to compute the additional processes, such as evaporation and the release of minimum environmental flows that need to be taken into account given the long duration of the simulation. During an optimization process, simulating each potential solution using both a mass balance and a hydraulic model would increase considerably the computational time, particularly if data transfer between the two models was required. It is therefore suggested that the primary simulation tool should be a hydraulic solver. Rainfallrunoff modeling could be performed pre-optimization, and supplemental code added to a hydraulic model to account for functionality of a mass balance model. This would allow for consideration of the evaporation from and rainfall directly to reservoirs, changes to demands based on water restrictions and environmental flows that depend on the combined volume of two reservoirs (Spring

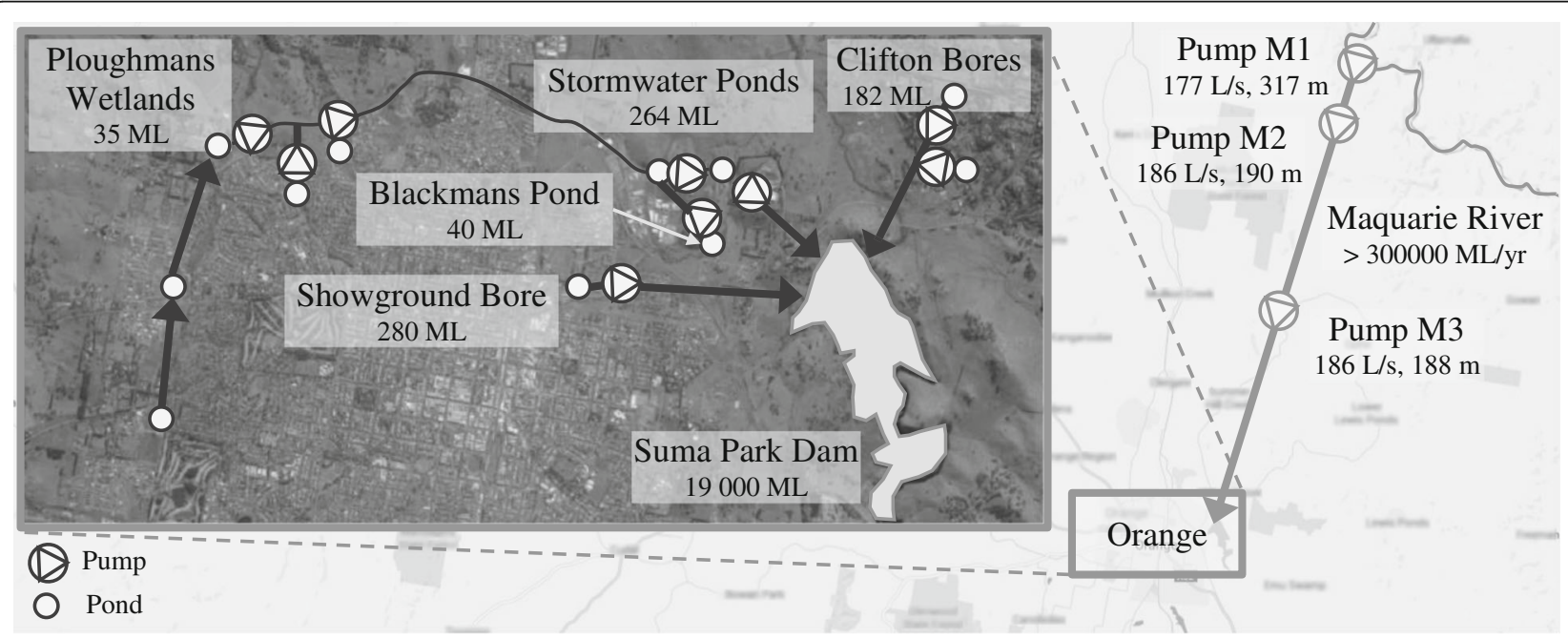

Fig. 10 Orange integrated supply system layout and data 
Table 8 Constraints for the Orange integrated supply system

\begin{tabular}{ll}
\hline Constraint & Value \\
\hline Macquarie River Environmental Flow & $>108 \mathrm{ML} /$ day \\
Blackmans' Creek Environmental Flow & $>20 \mathrm{ML} /$ day \\
Ploughmans' Creek Environmental Flow from Pump S4 & $>0.4 \mathrm{ML} /$ day \\
Ploughmans' Creek Environmental Flow from Pump S5 & $>2 \mathrm{ML} /$ day \\
Ploughmans' Creek Environmental Flow from Pump S6 & $>2 \mathrm{ML} /$ day \\
Clifton Grove (Shearing Shed and Bore 5) Aquifer & $<182 \mathrm{ML} /$ year \\
Extraction & $<280 \mathrm{ML} /$ year \\
Showground Aquifer Extraction & $<12 \mathrm{ML} /$ day \\
\hline Macquarie River Extraction License
\end{tabular}

Creek and Suma Park), infiltration losses when transferring water between reservoirs and peak power demand charges.

Another important issue to consider is what simulation time step should be used. Using a shorter time step will increase the accuracy of this hydraulic analysis and often results in feasible optimization times for storages that empty or fill in a day or two (as would likely be the case for the stormwater ponds and Macquarie pipeline balancing storages). Simulating the behavior of Suma Park dam is more challenging, however, as the variations in the water levels can have a period of several years. Thus, the computation times with a short time step become prohibitively long. A balance needs to be found between using a short enough time step for the detailed hydraulics and a long simulation time for the large storages without having a prohibitively large computational time. Given the data availability (there is 118 years of rainfall and inflow data available, with a daily time step) the time step chosen is 1 day.

Given that the time-step is automatically shortened by the hydraulic solver chosen (EPANET in this case), the model of the real system has been simplified in order to avoid excessive computational times. In particular, given that the levels in the balancing storages along the Macquarie pipeline vary rapidly, these storages were removed and the pipeline simulated with two parallel pumps, each representing the equivalent of the three stages of pumping (that is, the pump curves for Pumps M1a and b in Fig. 2 were adjusted such that they represented Pumps M2a, M3a and Pumps M2b, M3b as well). This simplification is considered acceptable as the pumps in series in the Macquarie pipeline will usually be operated at the same time, given that each pump will still be controlled also by the level of Suma Park Dam. Longer computational times were also caused by the small storages after the groundwater bores. The pumps used for extraction from the aquifers (Pumps G1a, G2a and G3a in Fig. 2) operate at relatively consistent rates, and as such they could be removed from the model and their energy use accounted for relative to the volume pumped from the second pump in each system (Pumps G1b, G2b and G3b respectively). To take into account the limited volume available from the groundwater bores, the storage tanks in the groundwater system each had a volume equivalent to a year's allocation for the respective bores. All of the stormwater pumps except for Pump S2c and Pump S3c, which are standby pumps and not in use, were included in the model. As well as the operating point of the pumps changing depending on the number of pumps used in parallel, there may be slight differences in efficiency and therefore energy use, and thus including all pumps here provided more accuracy.

All of the pumps included in the model were controlled using rule-based controls in EPANET, with conditions based on levels in one or more storages as well as time. Conditions based on downstream storages were considered as decision variables, while conditions based on upstream storages were fixed (Table 9). For the Macquarie pumps, there were also conditions based on the flow in the river to ensure that no water would be taken when there was not enough water available. There were four possible decision variables for each pump, a lower and upper trigger level in both the peak and off-peak time. For optimization of energy use, only two are required, as peak and off-peak tariffs are not considered. As the model was set up for other objectives including cost, which does use a peak and off-peak electricity tariff, the capability to choose different trigger levels in different periods was incorporated. A maximum of 15 pump switches per day per pump were allowed, and the end level of Suma Park Dam was constrained to $16 \mathrm{~m}$ (to be approximately the same as the start level). Based on license conditions, Macquarie River water can only be used when the Suma Park Dam level is below 90\%, so choices for Pump M1a and M1b trigger levels in Suma Park Dam are more restricted than for other pumps.

\section{Energy optimization results}

Minimization of pump energy use over the longer term is presented here as an example of optimization of this system. Note that the system is simulated over 1 year, at a daily time step in EPANET. Additional computer code was added to the EPANET hydraulic simulation to take into account other process such as rainfall to and evaporation from storages. This code essentially adds a mass balance component to the hydraulic simulation. Historical rainfall for the catchments in the system was modelled in MUSIC hydrologic software to develop inflow series for the ponds and reservoirs. For this optimization the year with the closest to average rainfall was used, however, other years of rainfall were available and this optimization could be extended to consider other climate conditions. 
Table 9 Decision variables and fixed controls for the Orange integrated supply system

\begin{tabular}{|c|c|c|}
\hline Pump station action & Storage(s) controlling operation & Decision variable or fixed \\
\hline Macquarie Pump M1a, M1b Off & Suma Park Dam Level High & Decision Variable \\
\hline Macquarie Pump M1a, M1b On & Suma Park Dam Level Low & Decision Variable \\
\hline Stormwater Pump S1a, S1b Off & $\begin{array}{l}\text { Holding Pond Level High } \\
\text { Blackmans Stormwater Pond Level Low }\end{array}$ & $\begin{array}{l}\text { Decision Variable } \\
\text { Fixed }\end{array}$ \\
\hline Stormwater Pump S1a, S1b On & $\begin{array}{l}\text { Holding Pond Level Low } \\
\text { Blackmans Stormwater Pond Level High }\end{array}$ & $\begin{array}{l}\text { Decision Variable } \\
\text { Fixed }\end{array}$ \\
\hline Stormwater Pump S2a, S2b Off & $\begin{array}{l}\text { Batch Ponds Level High } \\
\text { Holding Pond Level Low }\end{array}$ & $\begin{array}{l}\text { Decision Variable } \\
\text { Fixed }\end{array}$ \\
\hline Stormwater Pump S2a, S2b On & $\begin{array}{l}\text { Batch Ponds Level Low } \\
\text { Holding Pond Level High }\end{array}$ & $\begin{array}{l}\text { Decision Variable } \\
\text { Fixed }\end{array}$ \\
\hline Stormwater Pump S3a, S3b Off & $\begin{array}{l}\text { Suma Park Dam Level High } \\
\text { Batch Ponds Level Low }\end{array}$ & $\begin{array}{l}\text { Decision Variable } \\
\text { Fixed }\end{array}$ \\
\hline Stormwater Pump S3a, S3b On & $\begin{array}{l}\text { Suma Park Dam Level Low } \\
\text { Batch Ponds Level High }\end{array}$ & $\begin{array}{l}\text { Decision Variable } \\
\text { Fixed }\end{array}$ \\
\hline Stormwater Pump S4a, S4b Off & $\begin{array}{l}\text { Holding Pond Level High } \\
\text { Mitchell Wetland Level Low }\end{array}$ & $\begin{array}{l}\text { Decision Variable } \\
\text { Fixed }\end{array}$ \\
\hline Stormwater Pump S4a, S4b On & $\begin{array}{l}\text { Holding Pond Level Low } \\
\text { Mitchell Wetland Level High }\end{array}$ & $\begin{array}{l}\text { Decision Variable } \\
\text { Fixed }\end{array}$ \\
\hline Stormwater Pump S5a, S5b Off & $\begin{array}{l}\text { Holding Pond Level High } \\
\text { Brooklands Wetland Level Low }\end{array}$ & $\begin{array}{l}\text { Decision Variable } \\
\text { Fixed }\end{array}$ \\
\hline Stormwater Pump S5a, S5b On & $\begin{array}{l}\text { Holding Pond Level Low } \\
\text { Brooklands Wetland Level High }\end{array}$ & $\begin{array}{l}\text { Decision Variable } \\
\text { Fixed }\end{array}$ \\
\hline Stormwater Pump S6a, S6b Off & $\begin{array}{l}\text { Holding Pond Level High } \\
\text { Somerset Wetland Level Low }\end{array}$ & $\begin{array}{l}\text { Decision Variable } \\
\text { Fixed }\end{array}$ \\
\hline Stormwater Pump S6a, S6b On & $\begin{array}{l}\text { Holding Pond Level Low } \\
\text { Somerset Wetland Level High }\end{array}$ & $\begin{array}{l}\text { Decision Variable } \\
\text { Fixed }\end{array}$ \\
\hline Groundwater Pump G1 Off & Suma Park Dam Level High & Decision Variable \\
\hline Groundwater Pump G1 On & Suma Park Dam Level Low & Decision Variable \\
\hline Groundwater Pump G2 Off & Suma Park Dam Level High & Decision Variable \\
\hline Groundwater Pump G2 On & Suma Park Dam Level Low & Decision Variable \\
\hline Groundwater Pump G3 Off & Suma Park Dam Level High & Decision Variable \\
\hline Groundwater Pump G3 On & Suma Park Dam Level Low & Decision Variable \\
\hline
\end{tabular}

NSGAII (Non-dominated Sorting Genetic Algorithm II) software was used for the optimization, with five random seeds, a population size of 50, 100 generations and probabilities of crossover and mutation of 0.8 and 0.02 respectively. In the best solution found, the system used a total of $793 \mathrm{MWh}$ of energy over the entire year. Table 10 shows the volume of water pumped from each source to Suma Park Dam (and supplied from the local catchment) and the energy used by each of the pumps for the optimal solution. Pumping from the Macquarie is very energy intensive so this is only used at the very end of the simulation when the level in Suma Park Dam is very low, in order to achieve the end target level constraint (Figs. 11 and 12). Groundwater and stormwater sources are used initially to increase the level of Suma Park Dam to its maximum, and then not used again until around Day 160 when the level in the dam has dropped again. Only one of the Macquarie pumps is used, as, despite operating at a lower energy efficiency point, it uses less energy overall than operating two pumps in parallel. In dryer years, both pumps may need to be utilized in order to ensure supply to Suma Park Dam. Nearly all of the available groundwater license is used; G1 and G2 have a combined license of $180 \mathrm{ML} /$ year, and G3 $280 \mathrm{ML} /$ year. Groundwater is more energy intensive than stormwater, however, it can be used at any time throughout the year, while stormwater is reliant of inflow. Most of the stormwater provided to Suma Park Dam came from the Blackman's Creek scheme (S1) rather than the Ploughman's Creek scheme (S4, S5 and S6). While the storage capacity of the Blackman's Creek scheme is much lower, the pump capacity and energy efficiency is much greater than in the Ploughman's Creek scheme, so it provides more water. 
Table 10 Volume of water pumped/supplied and energy used in the optimal energy solution

\begin{tabular}{|c|c|c|c|c|}
\hline Source & Pump & $\begin{array}{l}\text { Volume } \\
\text { (ML) }\end{array}$ & $\begin{array}{l}\text { Energy } \\
\text { (MWh) }\end{array}$ & $\begin{array}{l}\text { Energy Rate } \\
\text { (MWh/ML) }\end{array}$ \\
\hline \multirow[t]{3}{*}{ Macquarie River } & M1a & 0 & 0 & 0 \\
\hline & $\mathrm{M} 1 \mathrm{~b}$ & 74 & 150 & 2.02 \\
\hline & Total & 74 & 150 & 2.02 \\
\hline \multirow[t]{4}{*}{ Groundwater $^{a}$} & G1 & 24 & 11 & 0.46 \\
\hline & $\mathrm{G} 2$ & 146 & 79 & 0.54 \\
\hline & G3 & 235 & 106 & 0.45 \\
\hline & Total & 405 & 196 & 0.48 \\
\hline \multirow[t]{13}{*}{ Stormwater } & S1a & 258 & 39 & 0.15 \\
\hline & $\mathrm{s} 1 \mathrm{~b}$ & 479 & 71 & 0.15 \\
\hline & S2a & 828 & 65 & 0.08 \\
\hline & $\mathrm{s} 2 \mathrm{~b}$ & 237 & 21 & 0.09 \\
\hline & S3a & 1022 & 170 & 0.17 \\
\hline & S3b & 22 & 5.5 & 0.25 \\
\hline & S4a & 178 & 41 & 0.23 \\
\hline & S4b & 12 & 3.1 & 0.27 \\
\hline & S5a & 24 & 4.8 & 0.20 \\
\hline & $\mathrm{S} 5 \mathrm{~b}$ & 56 & 11 & 0.19 \\
\hline & S6a & 60 & 11 & 0.18 \\
\hline & S6b & 26 & 5.0 & 0.19 \\
\hline & Total $^{b}$ & 1044 & 447 & 0.43 \\
\hline $\begin{array}{l}\text { Spring Creek and Suma } \\
\text { Park Catchment }\end{array}$ & - & $3865^{c}$ & - & - \\
\hline
\end{tabular}

${ }^{a}$ The energy consumption for the groundwater pumps includes both the transfer and bore pumps, i.e. the energy for Pump G1 includes G1a (not modelling in EPANET, energy use estimated from volume) and G1b (modelled in EPANET) ${ }^{\mathrm{b}}$ The total volume supplied by the stormwater schemes is measured as the combined volume supplied by Pumps S3a and S3b (which discharge to Suma Park Dam), while the total energy is the total of all pumps

'This is the volume supplied by the natural catchment for the town's consumption, the total inflow from the catchment is greater than this however some is used to provide environmental flows and some spills

\section{Conclusions}

A generalized framework for the optimization of the design and operation of water supply and distribution systems has been developed and two case study systems have been used as examples of how to apply it. The framework is comprised of several components; the options component describes the design and operational decision variables for the optimization, the infrastructure component covers the infrastructure aspects of the system that need to be modeled and their data requirements, the analysis component includes the simulation of the system and evaluation against the objectives and constraints, and finally the government policy component describes the regulations that may affect other aspects of the framework. These components fit within an optimization algorithm structure, which firstly generates potential solutions using the decision variables in the options component, models the system according to the infrastructure component and evaluates potential solutions using the analysis component. The evaluation of potential solutions then feeds into the solution space which informs how the decision variables are changed in the next set of potential solutions. Sensitivity analysis of parameters will significant uncertainty should be undertaken to ensure robust solutions. The framework also applies to simulation of systems prior to or without optimization.

The Ridge Park MAR Scheme Case Study harvests stormwater from an urban creek and stores it in an aquifer, to be extracted at a later time and used as nonpotable supply for irrigation of sporting fields and reserves. For this case study, and similar ones, the simulation of the system may be simplified by splitting the system into two parts, one for the components of the system used in winter operation (harvesting and injection) and one for the components used in summer operation (extraction and irrigation). This system highlighted the importance of simulation and analysis prior to optimization, in order to focus the formulation of the optimization problem. The Orange Integrated Supply

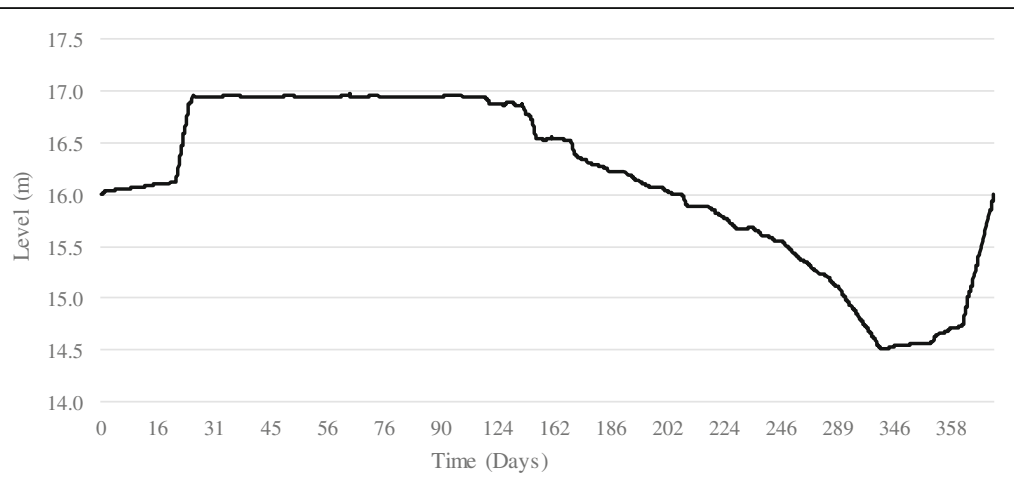

Fig. 11 Variation in Suma Park Dam level for the energy optimal solution 


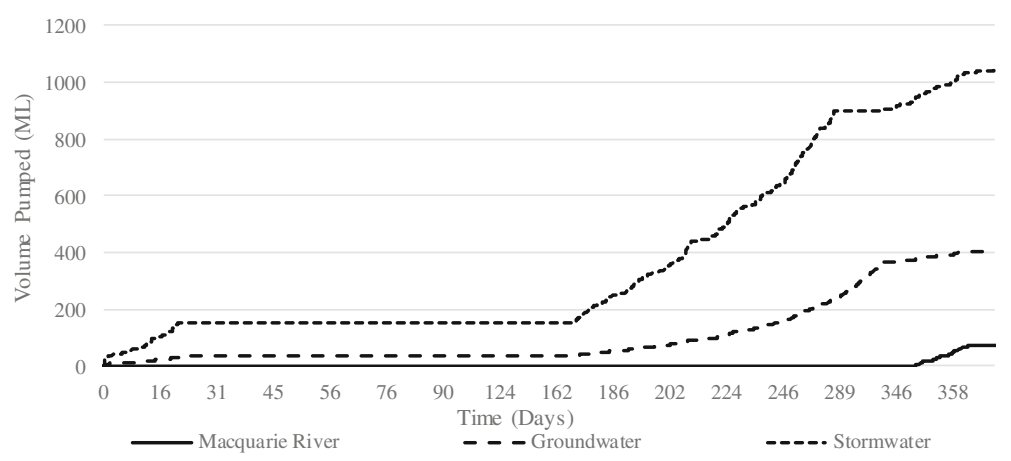

Fig. 12 Volume pumped from each source to Suma Park Dam for the energy optimal solution

System Case Study uses multiple water sources; natural catchment water, harvested stormwater, imported water and groundwater to supply potable demands. For this case study, finding an appropriate combination of simulation models and time step and simulation duration is important in order to provide accuracy in representing both long- and short-term operations without excessive computational times. Optimization of pump energy use for this system indicated that the groundwater and stormwater supplies are more desirable to supplement natural inflows than the imported water from the Macquarie River, which required a lot of energy to transfer water over a long distance and against a high elevation head.

The framework is generalized, and so could be applied to other water supply and distribution systems, particularly those using non-traditional water sources, to optimize their design and operation. While the framework attempts to cover all aspects of water supply in a generalized manner, it does have some limitations. Along with the supply of water, there will always be a need to manage wastewater. Apart from considering recycled wastewater as a source, this framework does not cover wastewater systems in terms of collection, transport, treatment and potential discharge of wastewater into the environment. Treatment of raw water supplies is included in the framework, however, the details of such treatment and measurement of water quality throughout a water distribution system are not focused on as much as the design and operation of the systems. A difficulty of applying this framework will be the definition of the boundary of a system and which aspects should be analyzed. Currently, there does not exist commercial software that has all of the capabilities considered in the framework (i.e. both hydrologic and hydraulic simulation). This means that specialist simulation models may need to be developed for particular systems (as was done for the second case study). Future developments in simulation software may reduce the difficultly of combining hydrologic, mass balance and hydraulic considerations and remove the need for specialist tools built for individual systems. In the future, the framework should be tested with other case study systems to fully investigate its benefits.

\section{Additional files}

Additional file 1: CS1 Ridge Park Data Summary. (PDF 548 kb)

Additional file 2: CS1 Ridge Park Hydrological Data. (XLSX 3786 kb)

Additional file 3: CS2 Orange Data Summary. (PDF $537 \mathrm{~kb}$ )

Additional file 4: CS2 Orange Hydrological Data. (XLSX 13245 kb)

\section{Abbreviations}

AMALGAM: A Multi-ALgorithm Genetically Adaptive Multi-objective method; DEWNR: Department of Environment, Water and Natural Resources (South Australia); DoH: Department of Health (South Australia); EPA: Environmental Protection Agency (Australia); EPANET: Environmental Protection Agency NET hydraulic simulation software; GCM: Global circulation model; GHG: Green house gas; IPCC: Intergovernmental panel on climate change; MAR: Managed aquifer recharge; MUSIC: Model for urban stormwater improvement conceptualization; NSGAll: Non-dominated Sorting Genetic Algorithm II; SRES: Special report emissions scenarios; VSP: Variable speed pump; WDS: Water distribution system; WEAP: Water evaluation and planning system

\section{Acknowledgements}

The support of the Commonwealth of Australia through the Cooperative Research Centre program is acknowledged. This research was part of the CRC for Water Sensitive Cities Project C5.1 (Intelligent Urban Water Networks) and was supported by funding for post-doctoral research and a PhD top-up scholarship. The authors would like to thank Martin Haege (Geolyse), Chris Devitt (Orange City Council) and Matt Sanderson (The City of Unley) for providing information on the case study systems presented in this paper.

\section{Availability of data and materials}

The datasets supporting the conclusions of this article are included within the article and its additional files. This data has been collated by Lisa J. Blinco, the corresponding author of this paper. The following additional files are available:

- CS1 Ridge Park Data Summary.pdf

- CS1 Ridge Park Hydrological Data.xlsx

- CS2 Orange Data Summary.pdf

- CS2 Orange Hydrological Data.xlsx

\section{Competing interests}

The authors declare that they have no competing interests. 


\section{Authors' contributions}

LJB was responsible for the development of the conceptual framework, review of literature and drafting the manuscript. MFL provided feedback and recommendations in the development of the framework and helped to draft the manuscript. ARS provided feedback and recommendations in the development of the framework and helped to draft the manuscript. AM provided feedback and recommendations in the development of the framework and helped to draft the manuscript. All authors read and approved the final manuscript.

\section{Consent for publication}

Not applicable.

\section{Ethics approval and consent to participate}

Not applicable.

\section{Publisher's Note}

Springer Nature remains neutral with regard to jurisdictional claims in published maps and institutional affiliations.

\section{Received: 9 November 2016 Accepted: 27 March 2017} Published online: 12 April 2017

\section{References}

Ashbolt S, Maheepala S, Perera BJC (2014) A framework for short-term operational planning for water grids. Water Resour Manag 28:2367-2380. doi:10.1007/s11269-014-0620-4

Basupi I, Kapelan Z (2015) Flexible water distribution system design under future demand uncertainty. J Water Resour Plan Manag 141(4). doi:10.1061/ (ASCE)WR.1943-5452.0000416

Becker N, Lavee D, Katz D (2010) Desalination and alternative water-shortage mitigation options in Israel: a comparative cost analysis. J Water Resour Prot 2:1042-1056. doi:10.4236/jwarp.2012.212124

Beh EHY, Dandy GC, Maier HR, Paton FL (2014) Optimal sequencing of water supply options at the regional scale incorporating alternative water supply sources and multiple objectives. Environ Model Softw 53:137-153. doi:10.1016/j.envsoft.2013.11.004

Beh EHY, Maier H, Dandy GC (2015) Adaptive, multiobjective optimal sequencing approach for urban water supply augmentation under deep uncertainty. Water Resour Res 51. doi:10.1002/2014WR016254

Blinco L, Simpson AR, Lambert MF, Auricht CA, Hurr NE, Tiggemann SM, Marchi A Genetic algorithm optimization of operational costs and greenhouse gas emissions for water distribution systems. In: 16th Conference on Water Distribution System Analysis, Bari, Italy, 14-17 July 2014. Procedia Engineering, pp 509-516. doi:10.1016/j.proeng.2014.11.246

Bogardi JJ, Dudgeon D, Lawford R, Flinkerbusch E, Meyn A, Pahl-Wostl C, Vielhauer K, Vörösmarty C (2012) Water security for a planet under pressure: interconnected challenges of a changing world call for sustainable solutions. Curr Opin Environ Sustain 4:35-43. doi:10.1016/j.cosust.2011.12.002

Cai X, Zeng R, Kang WH, Song J, Valocchi AJ (2015) Strategic planning for drought mitigation under climate change. J Water Resour Plan Manag 141(9). doi:10.1061/(ASCE)WR.1943-5452.0000510

Campisano A, Modica C (2012) Optimal sizing of storage tanks for domestic rainwater harvesting in Sicily. Resour Conserv Recycl 63:9-12. doi:10.1016/j. resconnrec.2012.03.007

Chung G, Lansey K, Blowers P, Brooks P, Ela W, Stewart S, Wilson P (2008) A general water supply planning model: evaluation of decentralized treatment. Environ Model Softw 23:893-905. doi:10.1016/j.envsoft.2007.10.002

Cook C, Bakker K (2012) Water security: debating an emerging paradigm. Glob Environ Chang 22:94-102. doi:10.1061/j.gloenvcha.2011.10.011

Dandy GC, Simpson AR, Murphy $\sqcup$ (1996) An improved genetic algorithm for pipe network optimization. J Water Resour Res 32(2):449-458. doi:10.1029/95WR02917

Dawadi S, Ahmad S (2013) Evaluating the impact of demand-side management on water resources under changing climate conditions and increasing population. J Environ Manag 114:261-275. doi:10.1016/j.jenvman.2012.10.015

Deb K, Pratap A, Agarwal S, Meyarivan T (2002) A fast and elitist multiobjective genetic algorithm: NSGA-II. Trans Evol Comput 6(2):182-197

Dobbie MF, Brown RR (2012) Risk perceptions and receptivity of Australian urban water practitioners to stormwater harvesting and treatment systems. Water Sci Technol Water Supply 12(6):888-894. doi:10.2166/ws.2012.069
Fearnside PM (2002) Time preference in global warming calculations: a proposal for a unified index. Ecol Econ 41(1):21-31. doi:10.1016/\$0921-8009(02)00004-6

Fielding KS, Gardner J, Leviston Z, Price J (2015) Comparing public perceptions of alternative water sources for potable use: the case of rainwater, stormwater, desalinated water, and recycled water. Water Resour Manag 29:4501-4518. doi:10.1007/s11269-015-1072-1

Friedman K, Heaney JP, Morales M, Palenchar M (2014) Analytical optimization of demand management strategies across all urban water use sectors. Water Resour Res 50:5475-5491. doi:10.1002/2013WR014261

Gollier C, Weitzman ML (2010) How should the distant future be discounted when discount rates are uncertain? Econ Lett 107:350-353. doi:10.1016/j. econlet.2010.03.001

Hwang AH-S, Valeo C, Draper D (2006) Public perceptions and attitudes toward stormwater recycling for irrigation. Can Water Resour J 31(3):185-196. doi:10.4296/cwrj3103185

IPCC (2000) In: Nakicenovic N, Swart R (eds) Special Report on Emissions Scenarios. Cambridge

IPCC (2007) Synthesis Report: Contribution of Working Groups I, II and III to the Fourth Assessment Report of the Intergovernmental Panel on Climate change Climate Change 2007. IPCC, Geneva

Londoño Cadavid C, Ando AW (2013) Valuing preferences over stormwater management outcomes including improved hydrologic function. Water Resour Res 49:4114-4125. doi:10.1002/wrcr.20317

Makropoulos CK, Natsis K, Liu S, Mittas K, Butler D (2008) Decision support for sustainable option selection in integrated urban water management. Environ Model Softw 23:1148-1460. doi:10.1016/j.envsoft.2008.04.010

Marchi A, Dandy GC, Maier HR (2016) Integrated approach for optimizing the design of aquifer storage and recovery stormwater harvesting schemes accounting for externalities and climate change. J Water Resour Plan Manag 142(4). doi:10.1061/(ASCE)WR.1943-5452.0000628

McArdle P, Gleeson J, Hammond T, Heslop E, Holden R, Kuczera G (2011) Centralised urban stormwater harvesting for potable reuse. Water Sci Technol 63(1):16-24. doi:10.2166/wst/2011.003

Miller S, Shermer H, Semiat R (2015) Energy and environmental issues in desalination. Desalination 366:2-8. doi:10.1016/j.desal.2014.11.034

Milly PCD, Betancourt J, Falkenmark M, Hirsch RM, Kundzewicz ZW, Lettenmaier DP, Stouffer RJ (2008) Stationary is dead: whither water management? Science 319:573-574. doi:10.1126/science.1151915

Montgomery Watson Harza (2011). Orange drought relief connection concept investigation report, report prepared for the Orange City Council. http:// watersecurity.orange.nsw.gov.au/client_images/1046362.pdf

Mpelasoka FS, Chiew FHS (2009) Influence of rainfall scenario construction methods on runoff projections. J Hydrometeorol 10(5):1168-1183. doi:10.1175/2009jhm1045.1

Muga HE, Mihelcic JR (2008) Sustainability of wastewater treatment technologies. J Environ Manag 99:437-447. doi:10.1016/j.jenvman.2007.03.008

Nagal R (2015) Making direct potable reuse a reality. J Am Water Works Assoc 107(7):76-82. doi:10.5942/jawwa.2015.107.0103

Naylor T, Moglia M, Grant AL, Sharma AK (2012) Self-reported judgements of management and governance issues in stormwater and greywater systems. J Clean Prod 29-30:144-150. doi:10.1016/j.jclepro.2012.02.003

Nicklow J, Reed P, Savic D, Dessalegne T, Harrell L, Chan-Hilton A, Karamouz M, Minsker B, Ostfeld A, Singh A, Zechman E (2010) State of the art for genetic algorithms and beyond in water resources planning and management. J Water Resour Plan Manag 136(4):412-432. doi:10.1061/(ASCE)WR.1943-5452.0000053

Oron G, Adel M, Agmon V, Friedler E, Halperin R, Lesham E, Weinberg D (2014) Greywater use in Israel and worldwide: standards and prospects. Water Res 58:92-101. doi:10.1016/j.watres.2014.03.032

Paton FL, Maier HR, Dandy GC (2013) Relative magnitudes of sources of uncertainty in assessing climate change impacts on water supply security for the southern Adelaide water supply system. Water Resour Res 49:1643-1667. doi:10.1002/wrcr.20153

Paton FL, Dandy GC, Maier HR (2014) Integrated framework for assessing urban water supply security of systems with non-traditional sources under climate change. Environ Model Softw 60:302-319. doi:10.1016/j.envsoft.2014.06.018

Rambaud SC, Torrecillas MJM (2005) Some considerations on the social discount rate. Environ Sci Policy 8:343-355. doi:10.1016/j.envsci.2005.04.003

Reis LFR, Walters GA, Savic D, Chaudhry FH (2005) Multi-reservoir operation planning using hybrid genetic algorithm and linear programming (GA-LP: an alternative stochastic approach. Water Resour Manag 19:831-848. doi:10.1007/s11269-005-6813-0 
Rodriguez C, van Buynder P, Lugg R, Blair P, Devine B, Cook A, Weinstein P (2009) Indirect potable reuse: a sustainable water supply alternative. Int J Environ Res Public Health 6(3):1174-1209. doi:10.3390/ijerph6031174

Roshani E, Filion YR (2014) Water distribution system rehabilitation under climate change mitigation scenarios in Canada. J Water Resour Plan Manag 141(4). doi:10.1016/(ASCE).WR.1943-5452.0000450

Rozos E, Makropoulos CK (2013) Source to tap urban water cycle modelling. Environ Model Softw 41:139-150. doi:10.1016/j.envsoft.2012.11.015

Seifi A, Hipel K (2001) Interior-point method for reservoir operation with stochastic inflows. J Water Resour Plan Manag 127(1):48-57. doi:10.1061/(ASCE)0733-9496(2001)127:1(48)

Stern NH (2006) Stern review: the economics of climate change. Cambridge University Press, Cambridge

Stokes CS, Simpson AR, Maier HR (2014) The cost-greenhouse gas emission nexus for water distribution systems including the consideration of energy generating infrastructure: an integrated conceptual optimization framework and review of literature. Earth Perspectives 1(9). doi:10.1186/2194-6434-1-9

Umapathi S, Chong MN, Sharma AK (2013) Evaluation of plumbed rainwater tanks in households for sustainable water resources management: a real-time monitoring study. J Clean Prod 42:204-214. doi:10.1016/j.jclepro.2012.11.006

Vrugt JA, Robinson BA (2007) Improved evolutionary optimization from genetically adaptive multimethod search. Proc Natl Acad Sci U S A 104(3):708-711. doi:10.1073/pnas.0610471104

Weitzman ML (2007) A review of the Stern review on the economics of climate change. J Econ Lit 45:703-724. doi:10.1257/jel.45.3.703

West C, Kenway S, Hassall M, Yuan Z (2016) Why do residential recycled water schemes fail? A comprehensive review of risk factors and impact on objectives. Water Res 102:271-281. doi:10.1016/j.watres.2016.06.044

Wu W, Maier HR, Simpson AR (2010a) Single-objective versus multiobjective optimization of water distribution systems accounting for greenhouse gas emissions by carbon pricing. J Water Resour Plan Manag 136(5):555-565. doi:10.1061/(ASCE)WR.1943.5452.0000072

Wu W, Simpson AR, Maier HR (2010b) Accounting for greenhouse gas emissions in multiobjective genetic algorithm optimization of water distribution systems. J Water Resour Plan Manag 136(2):146-155. doi:10.1061/(ASCE)WR.1943.5452.0000020

Wu W, Simpson AR, Maier HR (2012a) Sensitivity of optimal tradeoffs between cost and greenhouse gas emissions for water distribution systems to electricity tariff and generation. J Water Resour Plan Manag 138:182-186. doi:10.1061/(ASCE)WR.1943.5452.0000169

Wu W, Simpson AR, Maier HR, Marchi A (2012b) Incorporating variable-speed pumping in multi-objective genetic algorithm optimization of water distribution systems to reduce greenhouse gas emissions. J Water Resour Plan Manag 138(5):543-552. doi:10.1061/(ASCE)WR.1943.5452.0000195

Wu W, Maier HR, Simpson AR (2013) Multiobjective optimization of water distribution systems accounting for economic cost, hydraulic reliability, and greenhouse gas emissions. Water Resour Res 49(3):1211-1225. doi:10.1002/wrcr.20120

\section{Submit your manuscript to a SpringerOpen ${ }^{\circ}$ journal and benefit from:}

- Convenient online submission

- Rigorous peer review

- Immediate publication on acceptance

- Open access: articles freely available online

- High visibility within the field

- Retaining the copyright to your article 